\title{
First, do not degrade - an alternative view on polymer laser sintering
}

\author{
Arkadiusz J. Antończak ${ }^{\mathrm{a}^{*}}$, Mateusz Wieczorek ${ }^{\mathrm{a}}$, Paulina Dzienny ${ }^{\mathrm{a}}$, \\ Bartłomiej Kryszak ${ }^{\mathrm{b}}$, Anna Krokos ${ }^{\mathrm{b}}$, Piotr Gruber ${ }^{\mathrm{c}}$, Michał Olejarczyk ${ }^{\mathrm{c}}$, Małgorzata Gazińska ${ }^{\mathrm{b}}$ \\ ${ }^{a}$ Faculty of Electronics, Laser and Fibre Electronics Group, \\ ${ }^{\mathrm{b}}$ Faculty of Chemistry, Department of Engineering and Technology of Polymers, \\ ${ }^{c}$ Faculty of Mechanical Engineering/Centre of Advanced Manufacturing Technologies, \\ Wroclaw University of Science and Technology, Wyb. Wyspiańskiego 27, 50-370 Wrocław, Poland. \\ * Corresponding author. Tel.: +48 713204698. E-mail address: arkadiusz.antonczak@pwr.edu.pl.
}

\begin{abstract}
:
In the work, for the first time, the method of Dual Beam Laser Sintering of polymers (DBLS) was presented, in which, instead of heating the entire volume of the polymer throughout the entire process, a second, additional laser was used for selective in terms of volume and time heating of the material. The principle of operation and the design of the prototype are presented. Using the developed station, an experiment was carried out for sintering samples from technical polylactide powder as a function of selected process parameters. It confirmed the functionality of the method and proved that the sintering process can be controlled in a fairly wide range for the proposed method. A preliminary comparison of changes in the physicochemical properties of the obtained samples in relation to the samples sintered by standard laser sintering was carried out using Gel Permeation Chromatography, Fourier Transform Infrared Reflectance and Differential Scanning Calorimetry. The experiment showed that the presented method has the potential to limit the thermal degradation of sensitive polymer materials.
\end{abstract}

Keywords:

polymer laser sintering, dual beam laser sintering, polylactide PLA, polymer degradation, GPC, ATR-FTIR, DSC,

\section{Introduction}

Selective Laser Sintering (SLS) or more precisely polymer Laser Sintering (pLS) is one of the key polymer-based Additive Manufacturing (AM) technologies that belong to the powder bed fusion group [1]. This technology employs the laser beam to selectively sinter or melt polymer in powder shape to the form of a three-dimensional object. The geometry of produced object corresponds to the 3D model based on the data from medical imagining such as magnetic resonance imagining and computer tomography or more often modeled directly in CAD [2]. Before actual process a model is divided into a cross-section sequence, which is then reproduced [2]. The laser sintering process is conducted in a layer-by-layer manner, which starts with applying a thin layer of a polymer powder. Then raw material is preheated and lastly selectively scanned by a laser beam that causes the material to consolidate. The process is repeated until the part is built. One of the most important advantages of pLS technology is no requirements of support structures for manufacturing even the most complicated geometric shape. What's more pLS can process a wide range of thermoplastic materials, even biocompatible and biodegradable ones [3]. Technology is widely used in industry, not only for the manufacturing of prototypes but also a fully functional end-use parts in industries branches such as automotive, aerospace, sports, electronics as well as medical technology. pLS biomedical application is often reported as a method for production of patient-specific biological substitutes in an attempt to restore, maintain or improve tissue function [4].

The first pLS patent was granted in 1989 [5] yet technology is still in continuous development. Nowadays growth mainly focuses on preparing high-temperature devices, allowing to process polyaryletherketone (PAEK) family of semi-crystalline thermoplastics, but also a production-grade machines with faster build rates, quality systems with monitoring, or even controlled in a closed loop. Preferably these manufacturing machines should be ready for automation at a production plant. Examples of this development paths are production-oriented 
machines such as Integra P500 (EOS, Krailling, Germany), ProX SLS 6100 (3D Systems Inc. Rock Hill USA) and HT1001P (Farsoon Technologies, Hunan, China). Another development path of pLS on which researchers and companies focus, is overcoming one of the biggest disadvantages of technology - the thermal degradation of unfused powder. The average packing density of a prepared manufacturing process is about $10 \%$, which indicates that the unfused powder on every build process is $90 \%$ of a build chamber [6]. Given that the most popular pLS material, which covers about $95 \%$ of the pLS powder market [7], polyamide 12 (PA12) has to be regenerated before reusing in the next build job. Depending on the machine and powder manufacturer, used powder has to be mixed with a virgin one, typically process-ready powder consists a range of $30 \%$ to $50 \%$ of fresh powder and $70 \%$ to $50 \%$ used one [6]. Such a process is often called a powder regeneration. The reuse of waste powder is an issue that has at least two the most popular means for its solution: actual recycling of a polymer powder or modifications in hardware and process conditions. The first solution focuses mainly on recycling waste powder with a solvent-free process $[8,9]$, which allows to the significant reduction of virgin powder amount in mixing ratio. It has to be taken into account that it is a material-specific process, not every polymer can be recycled or even regenerated in typical for pLS method. In most cases, due to the domination of PA12 usage in powder bed fusion technologies, an effort is focused on polyamide powders. The second solution focuses on reducing the thermal ageing of a powder during the process, which is mainly due to the long-term exposure of a powder to near-melting temperatures (so-called sintering window) [3]. The example can be a beta-program announced at the end of 2020 by a service bureau - Materialise (NV, Belgium), which assumes selectively preheating a powder and not a whole build area [10]. However, the goal in both ways is to ultimately allow to reuse of $100 \%$ of the waste powder and thus reducing manufacturing costs along with having more environmentally friendly approach.

Beyond reusing waste powder thermal ageing plays important role in biocompatibility of polymer. The degradation can have numerous negative effects such as deformation and a decrease in surface quality (so-called orange peel effect) of a produced part [6]. Additionally to maintain the processability of degraded powder usually there is a need to adjust the process parameters. Adjustments help to avoid process errors such as curling and warpage, layer delamination, parts yellowing and others. In the case of biomedical applications thermal degradation often excludes the use of such a polymer product, especially in the applications of implants. The current approach in pLS technologies assumes the usage of only a fresh powder to ensure the biocompatibility of biomedical products. Numerous biopolymers can be processed using pLS technology, such as PEEK/HAp, PCL, PEEK, PLGA, PVA, PLLA [2]. Reported applications are ranging from biomedical prototypes and devices, drug and biomolecule delivery devices and scaffolds for tissue engineering [11-14]. One of the most interesting material to be used in pLS in the biomedical field is poly(L-lactide), a biodegradable polymer from the group of aliphatic polyesters. Its applications include, among others, the production of vascular stents [11], construction of orthopedic implants [12], and drug delivery systems [13]. The reasons for its wide usage are its biocompatibility and good mechanical and optical properties. It is used not only in powder-based additive manufacturing techniques but in extrusion-based printing technologies [15]. In this paper, we examine properties of the product and sintering possibilities in pLS construction development which can be addressed to the secondly described path for reducing powder waste - which is referred to as hardware and process conditions modifications.

The presented method differs significantly from the standard pLS technology in the way of the powder preheating. The assumption of the method was to reduce unnecessary maintenance of the polymer at an elevated temperature, both as a function of the process time and the volume of the material. This meant the elimination of heating the entire volume of the powder to the bed temperature during the entire process, and thus replacing the heating of the chamber with an additional, properly formed laser beam, which will only heat the volume of material surrounding the polymer sintering point. In the literature, the use of two laser beams for laser sintering was presented several times, but it concerned the possibility of increasing the working field [16], 
sintering ceramics [17] or increasing the ductility of metal powders sintered products [18]. In the presented work, for the first time, we demonstrate the possibility of using two laser beams during sintering polymers and the elimination of heaters, which should reduce the degree of degradation of both the sintered structures and the post-process material outside the sintering zone.

\section{The idea of laser sintering of polymer powders with the use of two laser beams}

First, don't degrade. This idea motivated us to develop and test an alternative method of laser sintering of polymer powders, which could reduce polymer degradation both inside and outside the sintering zone, saving valuable material, especially when using medical-grade polymers. Degradation, in particular reduction of the molecular weight of the polymer as a result of chain breakage and the formation of macromolecules of shorter length, is a complex process, depending both on the factors causing the degradation and on the environment in which the process occurs. With regard to laser sintering of polymers, the main degradation factors are the processing temperature of the polymer and the long exposure time to thermal effects. For many polymers, the degradation process has been well described in the literature. For polylactide (PLA), which was used in this work, thermal decomposition is a multi-stage process based mainly on intramolecular transesterification (macrocyclization) of the polymer [19]. The products of thermal degradation of polylactides $\left(-\left[\mathrm{CH}\left(\mathrm{CH}_{3}\right) \mathrm{COO}\right]_{\mathrm{n}}-\right)$ are therefore cyclic oligomers restoring the polymer structure, simple dimers, including lactide and products with a lower boiling point, in particular acetaldehyde $\left(\mathrm{CH}_{3} \mathrm{CHO}\right)$, ketene $\left(\mathrm{H}_{2} \mathrm{CCO}\right)$ and carbon monoxide and dioxide [20-22]. It has also been shown that PLA homolysis increases with temperature, especially above $270^{\circ} \mathrm{C}[23]$.

The assumption on which the presented method was based was to reduce unnecessary maintenance of the polymer at an elevated temperature, both as a function of the time of the process and the volume of the material. This directly meant the need to eliminate heating the entire volume of the powder to the bed temperature during the entire process, and thus to replace the classic heating of the entire chamber, usually carried out by heaters, with an additional, appropriately formed laser beam, which will only heat the volume of material surrounding the polymer sintering point. Before discussing the proposed method, it is necessary to explain a number of simplifications (design limitations) resulting from the willingness to adapt a readymade plotter laser system dedicated to subtractive processing to the experiment. It should also be noted that in the target solution, both the sintering beam and the heating beam can come from the same laser source, and the division of the radiation power can be obtained, for example, by means of an acousto-optical Bragg modulator. The theoretical analysis also shows that the heating beam should have a distribution similar to the Top-Hat profile, which was difficult to implement here due to the use of the plotter system (the change in the length of the optical path as a function of scanning the material surface made it impossible to use diffraction optics). Secondly, ultimately, the method should be developed based on fast galvanometric scanning, which will allow for more flexible selection of the scanning speed (typical for standard LS) and the use of diffraction optics to shape the aforementioned radiation distribution of the heating beam. These elements will be implemented in the next development version.

The plotter laser system (Speedy 300 by Trodat ${ }^{\circledR}$ ) has been adapted to the construction of the experimental system for Dual Beam Laser Sintering of polymer powders (DBLS). A simplified diagram of the approach is shown in Figure 1. The presented method uses two identical, independently controlled lasers (RF-excited pulsed $\mathrm{CO}_{2}$ laser with a wavelength of $10.6 \mu \mathrm{m}$ and output power up to $25 \mathrm{~W}$; Series $48-2$ Synrad, Inc.). The sintering beam (marked as $\mathrm{S}$ in the diagram) was created by focusing the radiation of the laser embedded in the system with a lens with a focal length of $63.5 \mathrm{~mm}$. The beam waist was $208 \mu \mathrm{m}$. The second laser beam was used to heat the surface of the powder $(\mathrm{H})$, with an exit diameter of about $3.5 \mathrm{~mm}$ (defined as $1 / \mathrm{e}^{2}$ ) and a divergence of $4 \mathrm{mrad}$, was enlarged 2 times with a beam expander (BEX-10.6-2Z1i from RonarSmith $\left.^{\circledR}\right)$, resulting in a diameter of about $8 \mathrm{~mm}$ on the surface of the powder. 
The functionality of the used laser system made it possible to scan the surface with a given speed and raster spacing (controlled by JobControl ${ }^{\mathbb{B}}$ software), as well as to control the parameters of the built-in sintering laser. The heating $(\mathrm{H})$ and sintering $(\mathrm{S})$ beams were placed coaxially in the focal plane of the sintering beam $(\mathrm{S})$. The beams simultaneously scanned the surface of the material. Each of them, however, had separately controlled power (through the duty cycle) and were independently turned on.

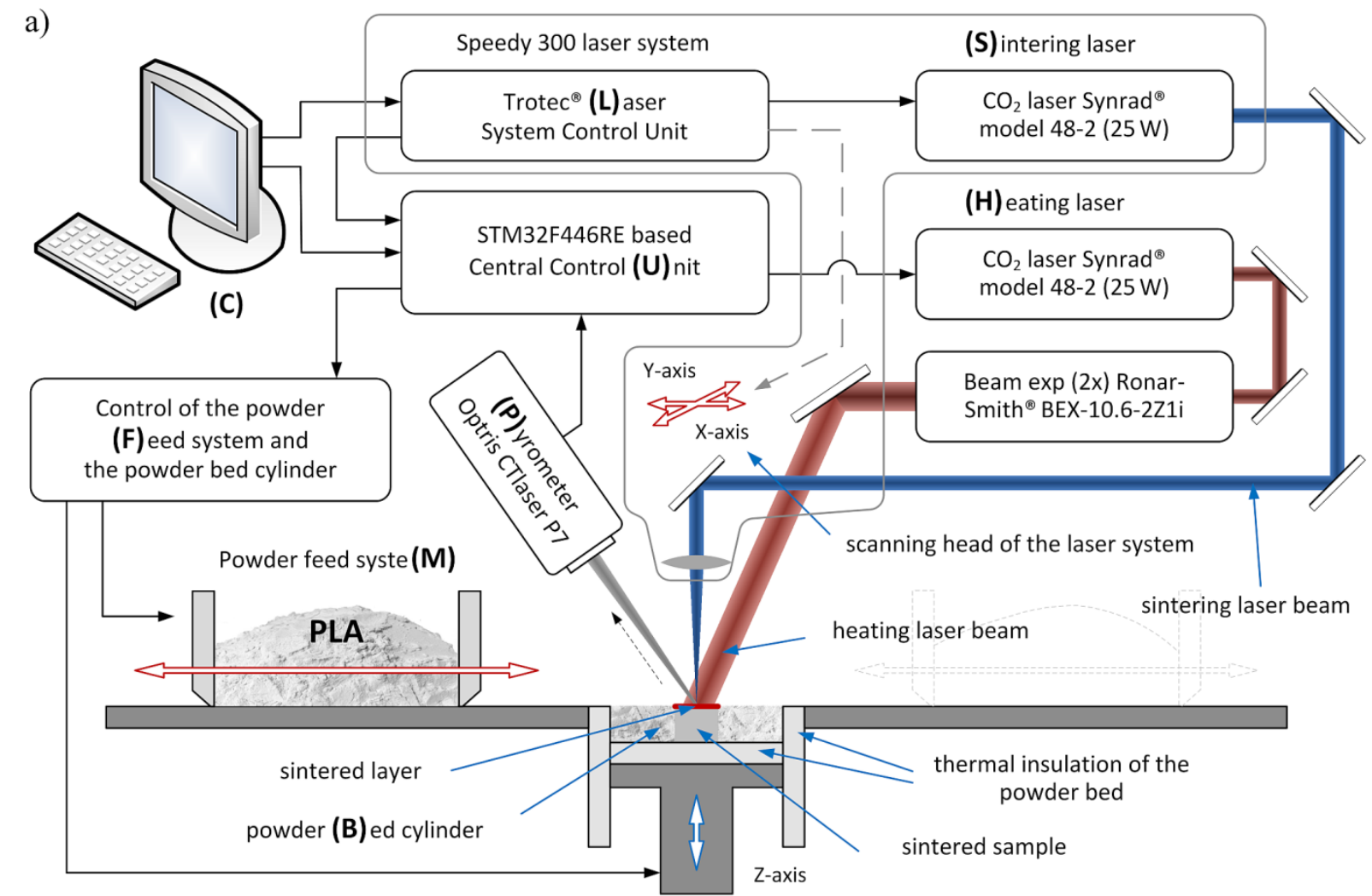

b)

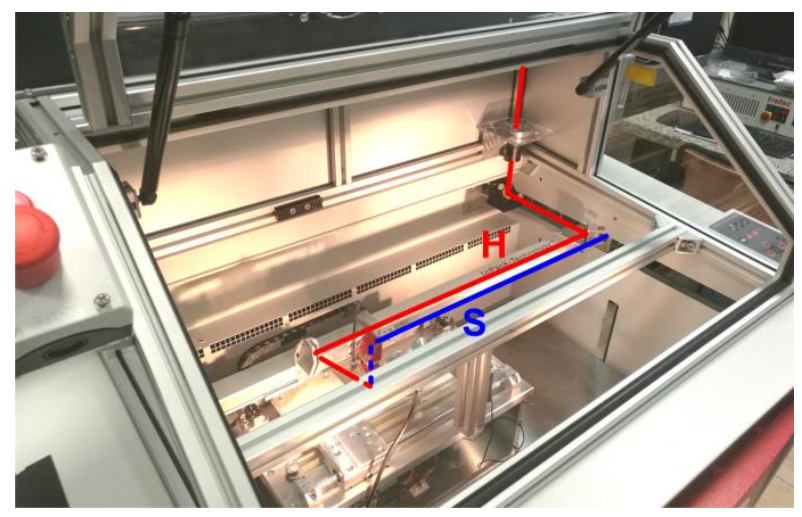

c)

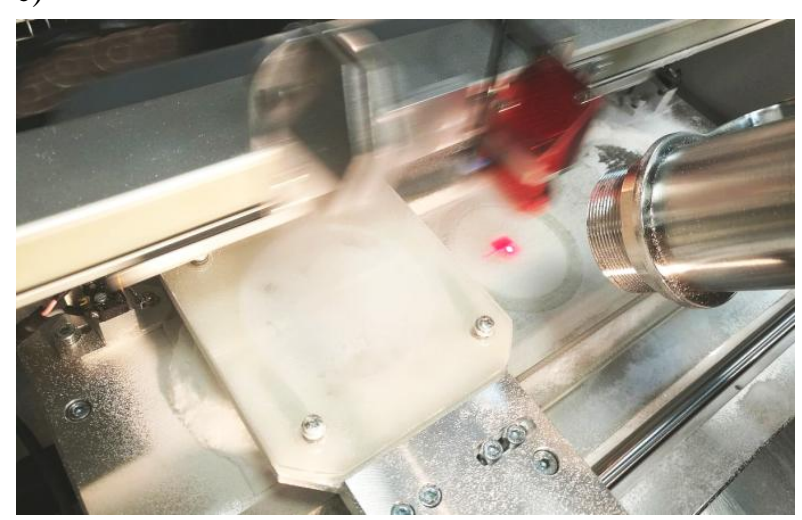

Fig. 1. Dual Beam Laser Sintering: a) block diagram of the experimental setup, b) photo of the work area with visualization of both laser beams, c) photo of the central part of the working field during sintering of the test sample

The small distance between individual pulses, depending on the sample, 25.4 or $50.8 \mu \mathrm{m}$ in combination with a large diameter of the heating beam $(8 \mathrm{~mm})$, allowed to obtain a high degree of overlap of pulses $\left(99.3-99.6 \%\right.$ equal in both directions $\left.O_{V x}=O_{V y}\right)$. This, in turn, made it possible to effectively heat the polymer surface using the heat accumulation effect to a given temperature using a relatively low power laser - on the order of a fraction to a few watt. In order to homogenize the temperature in the sintering zone and limit its gradient at the boundary of this area - the heating laser beams scanned an area larger than the outline of the sintered sample by approx. $4.0 \mathrm{~mm}$. In addition, in order to maintain a constant speed over the sintered surface, the amplitude of the head movement in the direction of the $\mathrm{X}$ axis was increased through 
acceleration and braking ramps on both sides $-10 \mathrm{~mm}$ on each side, respectively. To apply successive layers of powder with a controlled thickness $(\sim 100 \mu \mathrm{m})$ and to carry out the entire sintering process, an expansion module for the plotter system was developed, which is schematically shown at the bottom of Figure 1a and visualized in the photographs of Figure 1b and $\mathrm{c}$ (Figure 1c shows the system during sample sintering). The powder feeding system, which was also a container for the fresh polymer, was made in the form of a PA6 polyamide ring (abrasion-resistant) with an appropriately formed bottom edge, allowing for even distribution of the powder within the chamber (B). The powder receiving cylinder (B) with a diameter of $50 \mathrm{~mm}$ and a maximum depth of $50 \mathrm{~mm}$, in which the material was sintered after each layer, was lowered by a controlled value. The material surface temperature during sintering was controlled with an infrared sensor $(\mathrm{P})\left(\mathrm{C}\right.$ Tlaser $\mathrm{P} 7 \mathrm{Optris} \mathrm{GmbH}$ ) dedicated to measuring (range $0-710^{\circ} \mathrm{C}$ ) the temperature of polymers. The spectral range of the sensor $(7.9 \mu \mathrm{m})$ allowed for safe measurement of samples heated by $\mathrm{CO}_{2}$ laser radiation.

Due to the different method of heating the material, new process parameters for the DBLS method have been defined, in particular the temperature of the process $T_{P}$, understood as the maximum temperature to which the material was heated while illuminating it with both a heating beam $(\mathrm{H})$ and a sintering beam $(\mathrm{S})$, and the heating temperature $T_{H}$, which occurred with only the heating beam turned on. It is important to note, that the heating temperature is not equivalent to the bed temperature $T_{B}$ defined for the standard LS. In order to carry out the sintering process, a control system was developed (based on the STM32F446RE ARM Cortex M4), which control the power of the heating laser, powder bulk velocity, lowering the process chamber (B) and coordinates control with the laser plotter system. The main parameters that allowed for the control of the sintering process were the power of the sintering laser $P_{S}$, the process temperature $T_{P}$, the scanning speed of the sample $V$, the process resolution and the powder spreading speed. In addition, the initial and maximum power of the heating laser $P_{H}$ were determined. The surface temperature of the sintered sample was controlled at each layer. On the basis of the algorithm developed, the system automatically selected the power of the heating laser so as to obtain the desired process temperature (with a given tolerance) together with the preset sintering laser power. As a result of the heat accumulation effect, the power of the heating laser was gradually reduced automatically. The applied automation allowed to obtain stable sintering conditions within the entire sample. The sintering process of the samples was carried out on a support made of polylactide foil $(100 \mu \mathrm{m})$ temporarily stuck to the bottom of the cylinder (B) through thermal insulation. After the sample was made, the support foil was delaminated.

\section{Materials and methods}

\subsection{The material and the method of sample preparation}

In our research we used the commercially available PLA powder from Hebei Runk Tech Co., Ltd. The fraction with $0-100 \mu \mathrm{m}$ gradation about $30 \%$ of the unscreened powder was obtained by separate the material on the vibrating control screener KTS-V 600/1 using sieve with mesh size $100 \mu \mathrm{m}$. Due to the fact that the $0-100 \mu \mathrm{m}$ fraction ran out during the experiment, and the next purchased portion of the same material had completely different properties (including DSC thermograms), the authors decided to make the last two samples from the $100-200 \mu \mathrm{m}$ fraction.

\subsubsection{Clasic Laser Sintering (LS) - Machines}

Formiga P110 (EOS Krailling, Germany), commercial LS machine equipped with a downscaled working chamber in shape of a cylinder $(\varnothing 60 \times 60 \mathrm{~mm})$ was used to produce cube test samples. Formiga P110 operates using a $30 \mathrm{~W} \mathrm{CO}_{2}$ laser with optics that includes galvanometer scanners (bi-directional scanning, single pass of laser beam, $90^{\circ}$ rotation of scan vector between layers) and F-theta lens. The virgin and sieved PLA powder was used to produce test parts, fixed parameters were using along with variable laser power, detailed description is listed in Table 1. The manufacturing process preparation was made with dedicated PSW 3.6 software (EOS, Krailling, Germany). 
Table 1. Summary of the main process parameters for the laser sintering method

\begin{tabular}{|c|c|c|c|c|c|}
\hline Machine & $\begin{array}{c}\text { Layer thickness } \\
{[\mathrm{mm}]}\end{array}$ & $\begin{array}{c}\text { Temperature on } \\
\text { print surface }\left[{ }^{\circ} \mathrm{C}\right]\end{array}$ & $\begin{array}{c}\text { Scan spacing } \\
{[\mathrm{mm}]}\end{array}$ & $\begin{array}{c}\text { Scanning speed } \\
(\text { hatching})[\mathrm{mm} / \mathrm{s}]\end{array}$ & $\begin{array}{c}\text { Laser power } \\
{[\mathrm{W}]}\end{array}$ \\
\hline Formiga P110 & 0.1 & 86.5 & 0.15 & 2500 & $6 ; 10$ \\
\cline { 3 - 6 } & 130.0 & 0.25 & 1250 & $15 ; 24$ \\
\hline
\end{tabular}

\subsubsection{Dual Beam Laser Sintering (DBLS)}

In the experiment the prototype DBLS station described in point 2 was used. The samples were sintered at two process resolutions of 500 and 1000 DPI. In each case, the spacing between the laser pulses on the material surface was the same in both XY directions, i.e. 50.8 and $25.4 \mu \mathrm{m}$, respectively. It was subsequently determined at which maximum scanning speed the used plotter system allows to ensure a constant scanning speed within the sintered sample (with an area of $1 \times 1 \mathrm{~cm}^{2}$ ). This speed was determined and set at $710 \mathrm{~mm} / \mathrm{s}$. Then, for both resolutions, the limit values of the process temperature $T_{P}$ and the sintering laser power $P_{S}$ were determined using an experimental method. In simple terms, for high process temperatures of $T_{P}=200-220^{\circ} \mathrm{C}$, the limitation was the low power of the sintering laser. Reducing this power below a certain value (depending on the sample) resulted in an increase in the power of the heating laser $P_{H}$ (so as to collectively achieve the desired process temperature) to create an effect referred to in the literature as a "cake", consisting of powder agglomeration in the area surrounding the outline of the sintered sample. On the other hand, for the low process temperatures of $160-180^{\circ} \mathrm{C}$, too high power of the sintering laser was a limitation. Similarly, for certain, appropriately high values of the sintering laser power, during the process in which the heat accumulation effect occurred (corrected by reducing the power of the heating laser), the heating laser was completely switched off, which made it impossible to continue sintering. The values or ranges of common parameters used in the tests for individual samples are summarized in Table 2.

Table 2. Summary of the main process parameters for the dual beam laser sintering method

\begin{tabular}{|c|c|c|c|c|}
\hline \multirow{3}{*}{$\begin{array}{l}\text { Related to the } \\
\text { sintering laser }\end{array}$} & laser power & $P_{S}[\mathrm{~W}]$ & \multicolumn{2}{|c|}{$2.2-4.1 \mathrm{~W}^{* *}$} \\
\hline & focal length & $F[\mathrm{~mm}]$ & \multicolumn{2}{|c|}{63.5} \\
\hline & beam waist diameter $\left(@ 1 / \mathrm{e}^{2}\right)^{*}$ & $d_{0}[\mu \mathrm{m}]$ & \multicolumn{2}{|c|}{208} \\
\hline \multirow{2}{*}{$\begin{array}{l}\text { Related to the } \\
\text { heating laser }\end{array}$} & laser power & $P_{H}[\mathrm{~W}]$ & $<6.7$ W @ 500 DPI & $<4.7$ W@1000 DPI \\
\hline & beam diameter & $D_{0}[\mathrm{~mm}]$ & \multicolumn{2}{|c|}{$\sim 8.0$} \\
\hline \multirow{2}{*}{$\begin{array}{l}\text { Related to the } \\
\text { both laser }\end{array}$} & wavelength & $\Lambda[\mu \mathrm{m}]$ & \multicolumn{2}{|c|}{10.6} \\
\hline & pulse repetition rate & $P R R[\mathrm{~Hz}]$ & \multicolumn{2}{|c|}{5000} \\
\hline \multirow{6}{*}{$\begin{array}{l}\text { Other process } \\
\text { parameters }\end{array}$} & Resolution & DPI & \multicolumn{2}{|c|}{500 or 1000} \\
\hline & Hatching & $h[\mu \mathrm{m}] / \mathrm{LPI}$ & $25.4 / 1000$ & $50.8 / 500 * *$ \\
\hline & Scanning speed & $V[\mathrm{~mm} / \mathrm{s}]$ & \multicolumn{2}{|c|}{710} \\
\hline & Process temperature & $T_{P}\left[{ }^{\circ} \mathrm{C}\right]$ & \multicolumn{2}{|c|}{$160-220 * *$} \\
\hline & Laser heating temperature & $T_{H}\left[{ }^{\circ} \mathrm{C}\right]$ & \multicolumn{2}{|c|}{$64-133 * *$} \\
\hline & Layer to layer time & $t_{L}[\mathrm{~s}]$ & 〜30 s @500 DPI & 〜60 s @1000 DPI \\
\hline
\end{tabular}

$*$ - at the surface of the material; ** - depending on the case/sample; DPI (LPI) - dot (line) per inch.

\subsubsection{Test samples}

To initially determine the potential of the DBLS method as a reference, the standard LS method was used. For both methods (DBLS and LS), samples were made in the broadest possible range of parameters, from slightly baked (resembling a sugar cube) to the case of full melting, at which the sample became partially transparent. The samples selected for the assessment of changes in the physical and chemical properties of the material are presented in Table 3. Three groups of samples can be distinguished here. Reference samples (CRxx) for both used polymer fractions and one post-process reference for each method allowing the assessment of the degree of change in the material outside the sintering zone. Subsequently, four samples sintered with the standard LS method according to CMxx markings and two sets of samples sintered with the DBLS method (Cxx). The DBLS method allowed to obtain complex sample geometry - Figure 2, limited by the dimensions of the process chamber to a diameter of $30 \mathrm{~mm}$ and a height of about 
$40 \mathrm{~mm}$. It was assumed that for both methods, the test sample will be sintered in the form of a cube with dimensions of $1.0 \times 1.0 \times 1.0 \mathrm{~cm}^{3}$.

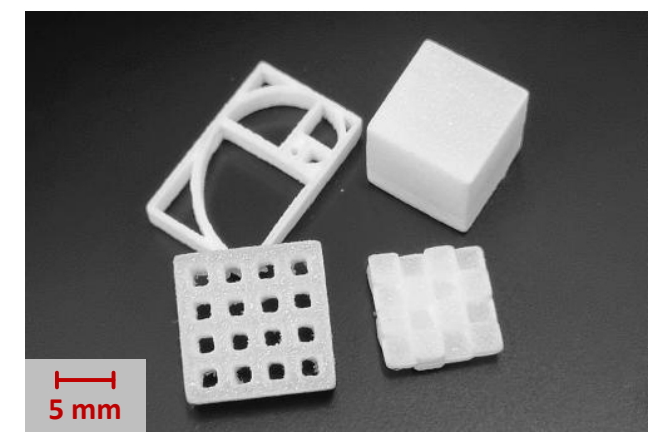

Fig. 2. Examples of samples sintered from polylactide (PLA) using the Dual Beam Laser Sintering method

Table 3. Names of samples and main parameters characterizing individual samples

\begin{tabular}{|c|c|c|c|c|c|c|}
\hline \multicolumn{2}{|c|}{ Sample name / method } & \multicolumn{5}{|c|}{ Process parameters / description } \\
\hline \multirow{4}{*}{ REF } & CR05 & \multicolumn{5}{|c|}{ REF_1 - pure powder $($ size $0-100 \mu \mathrm{m})$} \\
\hline & CR06 & \multicolumn{5}{|c|}{ REF_2 - pure powder (size $100-200 \mu \mathrm{m})$} \\
\hline & CR04 & \multicolumn{5}{|c|}{ REF_3 - LS after one processes (size $0-100 \mu \mathrm{m}$ ) } \\
\hline & CR03 & \multicolumn{5}{|c|}{ REF_4 - DBLS after several dozen processes (size $0-100 \mu \mathrm{m}$ ) } \\
\hline & & \multicolumn{5}{|c|}{$P_{S}[\% / \mathrm{W}]$} \\
\hline \multirow{4}{*}{ LS } & CM02 & \multicolumn{5}{|c|}{6} \\
\hline & CM05 & \multirow{2}{*}{\multicolumn{5}{|c|}{10}} \\
\hline & CM07 & \multirow{2}{*}{\multicolumn{5}{|c|}{$\frac{15}{21}$}} \\
\hline & CM09 & & & & & \\
\hline & & $h[\mu \mathrm{m}] / \mathrm{DPI}$ & $P_{S}[\mathrm{~W}]$ & $T_{P}\left[{ }^{\circ} \mathrm{C}\right]$ & $P_{H}[\mathrm{~W}]^{*}$ & $T_{H}\left[{ }^{\circ} \mathrm{C}\right]$ \\
\hline \multirow{15}{*}{ DBLS } & $\mathrm{C} 19$ & \multirow{7}{*}{$25.4 / 1000$} & \multirow{2}{*}{2.2} & 160 & 1.7 & 90 \\
\hline & $\mathrm{C} 20$ & & & 180 & 3.2 & 112 \\
\hline & $\mathrm{C} 23$ & & \multirow{3}{*}{2.6} & 160 & 0.5 & 70 \\
\hline & $\mathrm{C} 24$ & & & 180 & 2.1 & 100 \\
\hline & $\mathrm{C} 25$ & & & 200 & 2.7 & 133 \\
\hline & $\mathrm{C} 27$ & & \multirow{2}{*}{3.0} & 180 & 1.2 & 81 \\
\hline & $\mathrm{C} 28$ & & & 200 & 3.0 & 100 \\
\hline & $\mathrm{C} 30$ & \multirow{8}{*}{$50.8 / 500$} & \multirow{2}{*}{3.3} & 160 & 0 & 64 \\
\hline & $\mathrm{C} 31$ & & & 180 & 2.5 & 109 \\
\hline & $\mathrm{C} 32$ & & \multirow{4}{*}{3.7} & 160 & 0 & 72 \\
\hline & C33 & & & 180 & 0.5 & 75 \\
\hline & C34 & & & 200 & 2.5 & 113 \\
\hline & C35 & & & 220 & 4.3 & 131 \\
\hline & C36 & & \multirow{2}{*}{4.1} & 200 & 1.9 & 104 \\
\hline & C37 & & & 220 & 3.4 & 128 \\
\hline
\end{tabular}

where: $P_{S} / P_{H}-$ sintering / heating laser power; $T_{P} / T_{H}$ - process / heating temperature; $h$ - hatching; ${ }^{*}$ - at the end of the process

\subsection{Measurement techniques}

\subsubsection{Particle Size Distribution (PSD)}

Particle size distribution was determined using dry laser diffraction spectroscopy (Sympatec, HELOS/BR 4470 C, RODOS/T4, R4, Clausthal-Zellerfeld, Germany), with single particle measurement range $0.1-875 \mu \mathrm{m}$ (ISO 13220-1). Powder dispersion was made at 2 bar, vibration material feeder was used, in which feed rate was set to $100 \%$ along with $4.0 \mathrm{~mm}$ gap width.

\subsubsection{Dynamic Powder Flowability (DPF)}

Powder flowability in dynamic conditions was determined using Revolution Powder Analysis. This measurement corresponds to the conditions during LS powder application (using tools such as roller or blade). The method includes drum with an inner diameter of $84 \mathrm{~mm}$ and a width of $20 \mathrm{~mm}$ that rotates around its axis with controlled angular velocity. Measurements were made using the GranuDrum (Granutools, Belgium). The drum was filled with roughly $55 \mathrm{ml}$ of powder. 


\subsubsection{Scanning Electron Microscopy (SEM)}

The morphology of a powder particles were characterized using scanning electron microscopy (Zeiss SEM EVO MA25, Zeiss, Oberkochen, Germany). The samples were covered with Au (sputter current $40 \mathrm{~mA}$, sputter time: $50 \mathrm{~s}$ ) using the Quorum machine ensuring high-detailed analysis and resolution.

\subsubsection{Visualization of sample surfaces}

The Olympus Lext OLS5000 microscope equipped with objective of 20x magnification were used for imagining. In selected cases, a polarizer was used to extinguish unwanted reflections, to obtain a good image of highly reflective surfaces. All the samples were illuminated and imaged perpendicular to the surface. The photos of the whole samples were taken with a Canon 7D mark II digital camera equipped with a Canon EF $100 \mathrm{~mm}$ f/2.8L Macro IS USM lens.

\subsubsection{Gel Permeation Chromatography (GPC)}

Measurements were carried out by dissolving the polymer in chloroform $\mathrm{CHCl}_{3}(1.5 \mathrm{mg} / \mathrm{ml}$ solution) at $35^{\circ} \mathrm{C}$, with the eluent flow rate at $0.7 \mathrm{ml} / \mathrm{min}$ and volume of injection at $100 \mu \mathrm{l}$. The GPC analysis was carried out using a $300 \mathrm{~mm}$ long chromatographic column with $5 \mu \mathrm{m}$ particles (PLgel MIXED C from Agilent Technologies) and a refractive index detector (HP 1047 from Hewlett-Packard). In order to calibrate the chromatograph, we used polystyrene standards with molecular weights from 580 to 3993000 and a polydispersity within the range of $1.04-1.14$ (Polymer Laboratories Ltd.). Obtained data were processed using the PL Caliber GPC software.

\subsubsection{Attenuated Total Reflectance - Fourier Transform Infrared Reflectance (ATR-FTIR)}

The FTIR spectra were recorded using the FTIR NicoletTM 8700 spectrophotometer with the Smart Orbit Diamond ATR accessory (Thermo Fisher Scientific Inc., USA) within the range of $700-4000 \mathrm{~cm}^{-1}$ and with a $0.48 \mathrm{~cm}^{-1}$ step. The penetration depth was estimated at about $6 \mu \mathrm{m}$.

\subsubsection{Differential Scanning Calorimetr (DSC)}

DSC measurements were performed using differential scanning calorimeter DSC1 Mettler Toledo (Greifensee, Switzerland) equipped with Huber TC 100 intracooler. The instrument was calibrated using indium $\left(T_{m}=156.6^{\circ} \mathrm{C}, \Delta H_{m}=28.45 \mathrm{~J} / \mathrm{g}\right)$ and zinc $\left(T_{m}=419.7^{\circ} \mathrm{C}\right.$, $\Delta H_{m}=107.0 \mathrm{~J} / \mathrm{g}$ ) standards. Measurements were recorded at the temperature range of $25-200^{\circ} \mathrm{C}$ with heating and cooling rates of $10 \mathrm{~K} / \mathrm{min}$. Depending on the sample, the weight of the measured samples was $3.0-3.2 \mathrm{mg}$. The recorded DSC curves were normalized to the sample mass. The evaluation of the DSC curves has been performed using STAR ${ }^{\mathrm{e}}$ software ver.16.2.

\section{Results and discussion}

\subsection{Particle Size Distribution}

Particle size distribution is shown on Figure 3 with additional parameters listed in Table 4. Raw PLA powder has an asymmetrical distribution with particles above $200 \mu \mathrm{m}$, which if often referred as a theoretical maximum of a powder's range for LS [24].

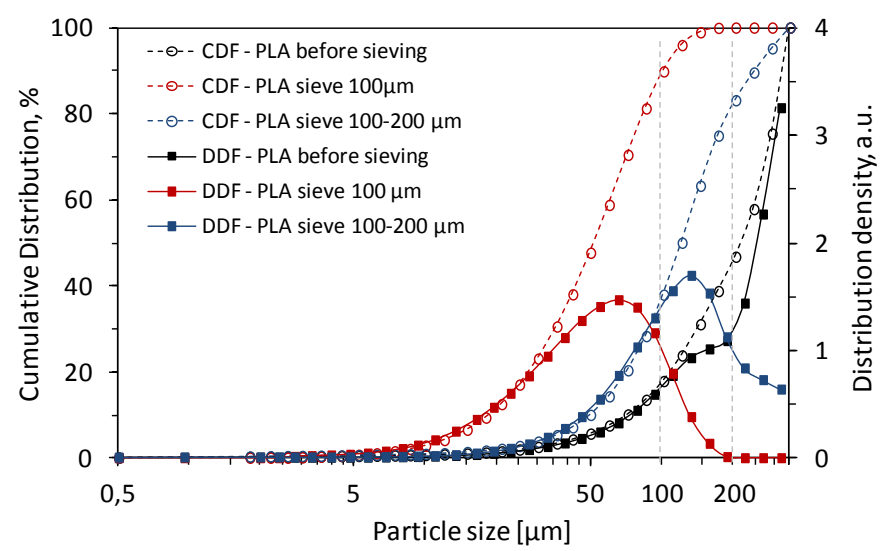

Fig. 3. Cumulative distribution (CDF) and distribution density (DDF) of the PLA 
Table 4. The first avalanche angle $(A A)$, flowing angle $\left(\alpha_{f}\right)$, cohesive index $\left(\sigma_{f}\right)$ and PSD of prepared powders

\begin{tabular}{|c|c|c|c|c|c|c|}
\hline \multirow[b]{2}{*}{ Material } & \multirow[b]{2}{*}{$A A\left[^{\circ}\right]$} & $\alpha_{f}\left[^{\circ}\right]$ & $\sigma_{f}[$ a.u. $]$ & \multirow{2}{*}{$\begin{array}{c}\mathrm{d} 50 \\
{[\mu \mathrm{m}]}\end{array}$} & \multirow[b]{2}{*}{$(\mathrm{d} 90-\mathrm{d} 10) / \mathrm{d} 50$} & \multirow{2}{*}{$\begin{array}{c}<10 \mu \mathrm{m} \\
{[\%]}\end{array}$} \\
\hline & & \multicolumn{2}{|c|}{$\begin{array}{c}\text { at } 30 \mathrm{rpm} \\
\text { (increasing speed) }\end{array}$} & & & \\
\hline PLA before sieving & 40.1 & 52.8 & 20.9 & 59.30 & 0.866 & 1.52 \\
\hline PLA sieve $100 \mu \mathrm{m}(\mathrm{CR} 05)$ & 52.2 & 60.8 & 36.8 & 52.12 & 1.642 & 2.80 \\
\hline PLA sieve 100-200 $\mu \mathrm{m}$ (CR06) & 56.5 & 65.2 & 50.7 & 122.04 & 1.637 & 2.06 \\
\hline
\end{tabular}

Practically the range is even narrower and it is from $20-80 \mu \mathrm{m}$. To achieve the desired range, the powder was sieved through a sieve with a $100 \mu \mathrm{m}$ pore size, which resulted in a more symmetrical and bimodal distribution which is more desirable in LS technology.

\subsection{Dynamic Powder Flowability}

Powder flowability properties are important due to ensuring homogenous delivery and application on work surface. Cohesive index in relation to rotating speed is showed in Figure 4.

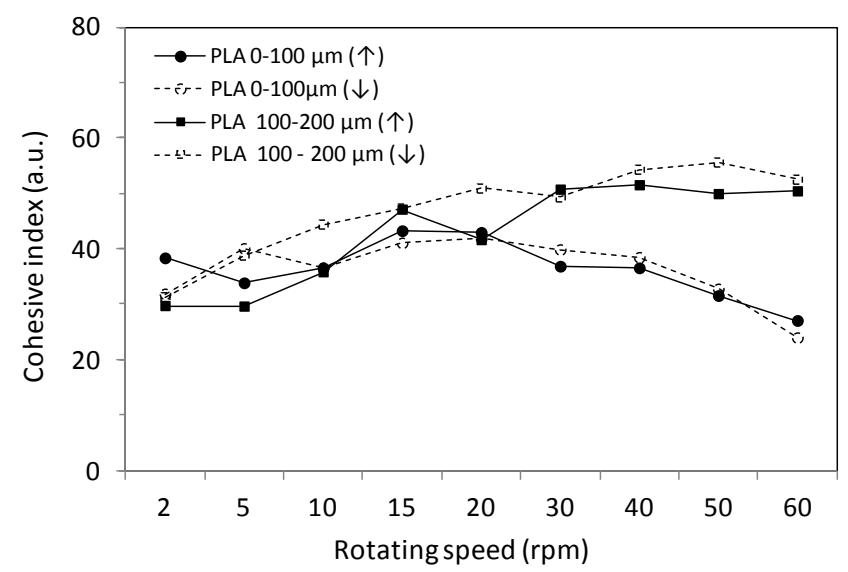

Fig. 4. Cohesive index curves as a function of the increasing $(\uparrow)$ and decreasing $(\downarrow)$ rotation speed for the prepared powders

Tested sieved PLA powder shows high values, which decreases as angular velocity increases. Cohesive index from ranges between 20 and 45 which are significantly lower than typically used in LS systems PA2200 which ranges between 10 and 25 indicating inferior PLA's flowability properties [25].

\subsection{Scanning Electron Microscopy}

SEM images shown in Figure 5 reveal edged powder particles with angular surface which indicates a manufacturing by a cryogenic milling method. Shown powder's morphology is known for negatively influencing flowability properties which explains worse flowability properties then reference of PA2200.

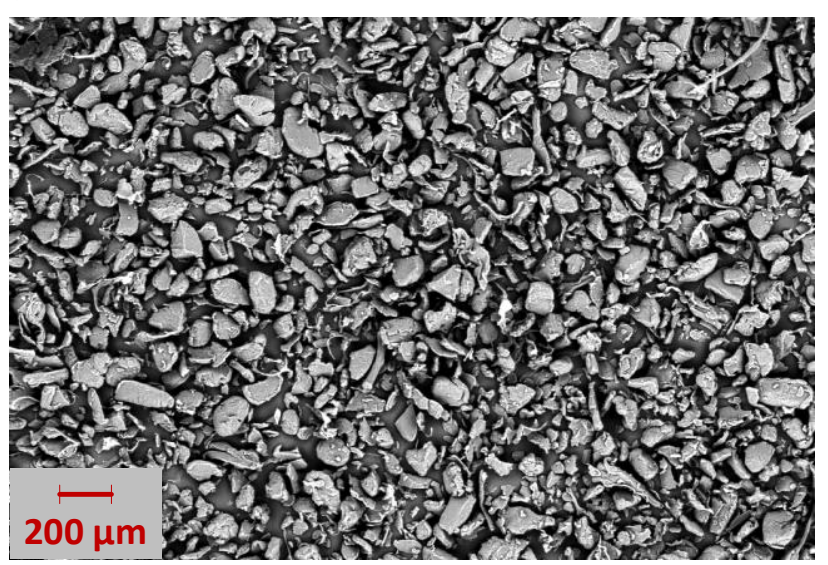

b)

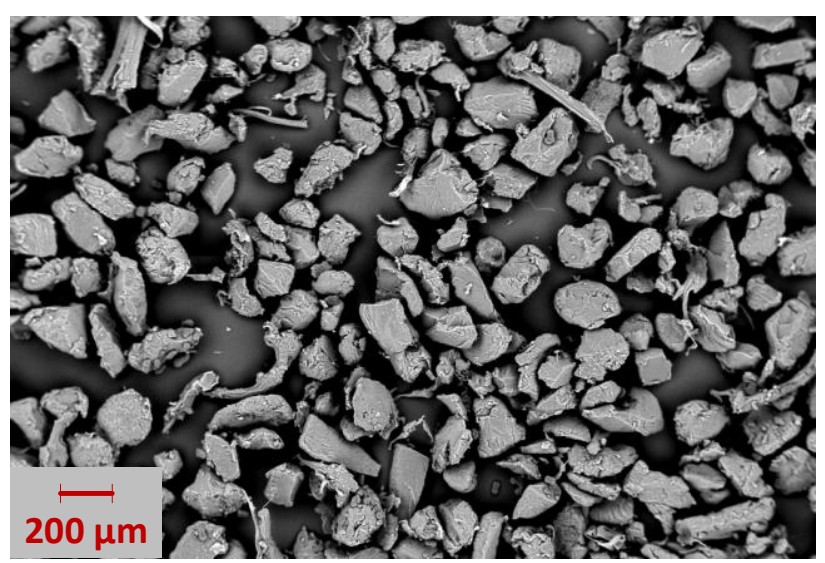

Fig. 5. SEM images for two fractions of PLA used in the experiment, a) sieved through a $100 \mu \mathrm{m}$ sieve, b) $200 \mu \mathrm{m}$ 


\subsection{Visualization of sample surfaces}

At the early stage of development of the presented method, due to hardware limitations and the finite amount of fractionated $(0-100 \mu \mathrm{m})$ PLA powder, it was assumed that the initial criterion for comparing samples would be the degree of sintering. For both methods (DBLS and LS) were made of the sample to the extent possible parameters from lightly sintered (e.g. C30 or CM02) to the case of complete melting, at which the sample became partially transparent (e.g. C37 or CM09). As the same result was obtained for both series of DBLS with a resolution of 500 and 1000 DPI, only the first case is presented below - Figure 6a. In order to be able to visually assess the surfaces of the samples in the tested method as a function of the sintering process parameters, no polymer powder was applied after scanning and sintering the surface of the last layer.

It is clearly visible that both with the increase of the process temperature $\left(T_{P}\right)$ and the sintering laser power $\left(P_{S}\right)$, the samples are sintered more strongly. The sample surface with the lowest sintering rate (C30) shows a significant amount of trapped gas (possibly air) bubbles due to incomplete flow of the material. Samples C35 - C37 presented differently. Here, the surface has been fully liquefied, and the visible defects are only loose-melted powder particles from the process atmosphere. The intermediate samples $(\mathrm{C} 31-\mathrm{C} 34)$ show a gradual reduction in the number of gas bubbles and an increase in surface homogeneity. The large dark areas visible on these samples are caused by undulations in the surface and light reflection beyond the aperture of the microscope objective. The visible minimum deviation from the given cube geometry in the case of the C35 sample is the effect of partial powder sintering outside the given zone - the socalled "cake".

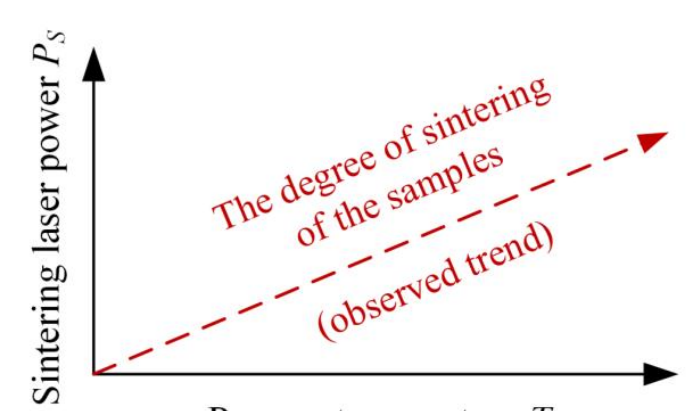

Process temperature $T_{P}$

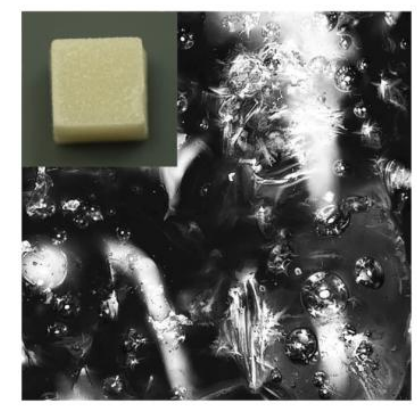

$\mathrm{C} 32\left(3.7 \mathrm{~W} / 160^{\circ} \mathrm{C}\right)$

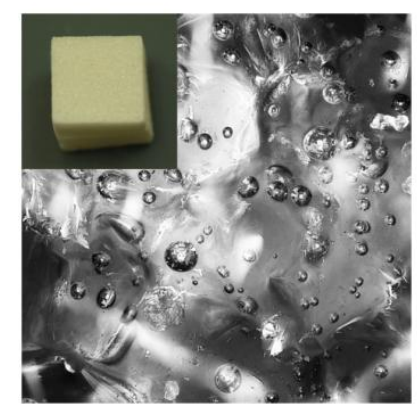

$\mathrm{C} 30\left(3.3 \mathrm{~W} / 160^{\circ} \mathrm{C}\right)$

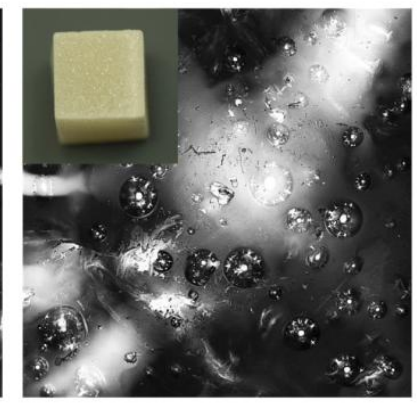

$\mathrm{C} 33\left(3.7 \mathrm{~W} / 180^{\circ} \mathrm{C}\right)$

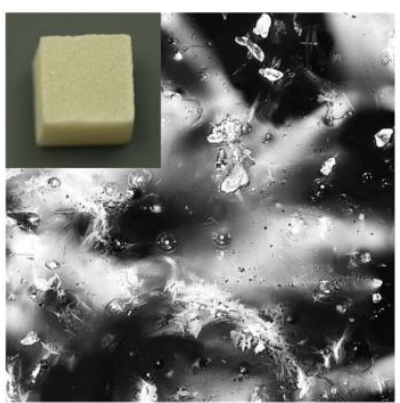

$\mathrm{C} 31\left(3.3 \mathrm{~W} / 180^{\circ} \mathrm{C}\right)$

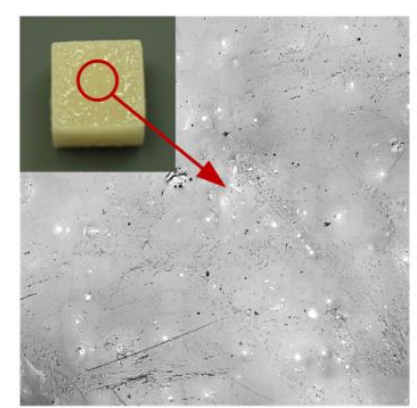

$\mathrm{C} 36\left(4.1 \mathrm{~W} / 200^{\circ} \mathrm{C}\right)$

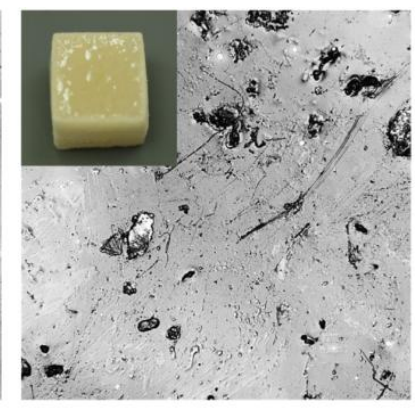

$\mathrm{C} 37\left(4.1 \mathrm{~W} / 220^{\circ} \mathrm{C}\right)$

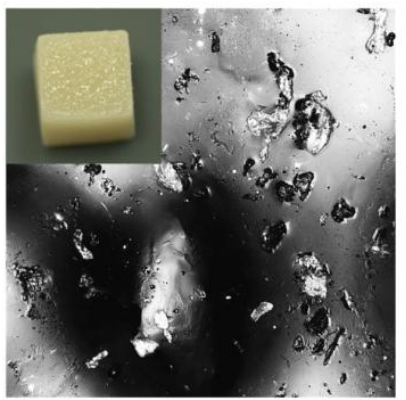

$\mathrm{C} 34\left(3.7 \mathrm{~W} / 200^{\circ} \mathrm{C}\right)$

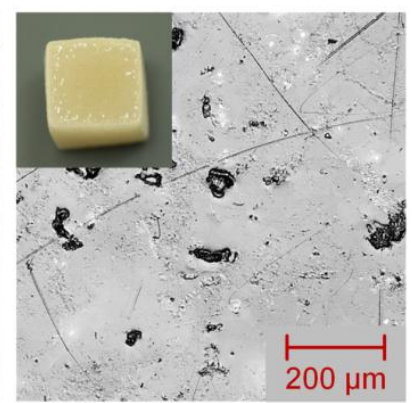

$\mathrm{C} 35\left(3.7 \mathrm{~W} / 220^{\circ} \mathrm{C}\right)$

Fig. 6a. Microscopic images $(640 \times 640 \mu \mathrm{m})$ visualizing the sintered surface of samples using the DBLS method for various process parameters for the 500 DPI $(h=50.4 \mu \mathrm{m})$ series and against their background, (top left corner) images of the entire samples $\left(1.0 \times 1.0 \times 1.0 \mathrm{~cm}^{3}\right)$. The $200 \mu \mathrm{m}$ scale applies to all microscopic images. Detailed parameters are summarized in Table 2 and 3 
However, this effect is much more visible on samples sintered with the standard LS method (CM07 and CM09) - Figure 6b. Unfortunately, due to the inability to exclude powder coating of samples in the final stage of their sintering using the LS method, it is not possible to assess the surface, and thus the degree of sintering. However, a more loose (void) structure can be seen in the case of a sample sintered with the power of $6 \mathrm{~W}$ (CM02).

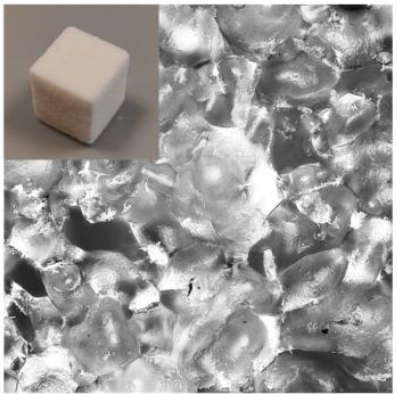

CM02 (6 W)

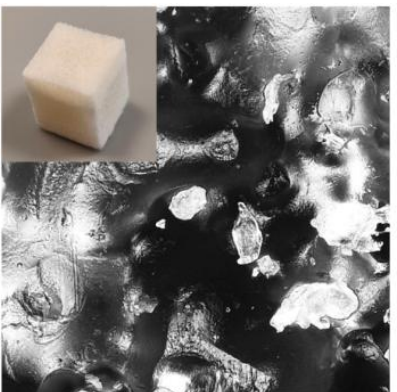

CM05 $(10 \mathrm{~W})$

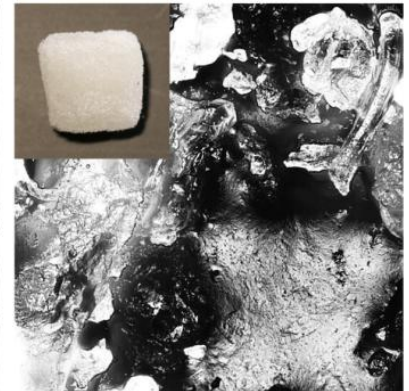

CM07 (15 W)

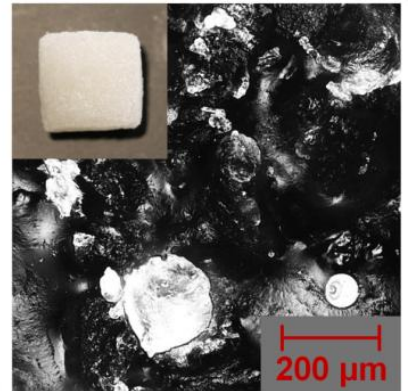

CM09 (21 W)

Fig. 6b. Microscopic images visualizing the sintered surface of samples using the standard LS method for different sintering laser powers and on their background (upper left corner) images of whole samples $\left(1.0 \times 1.0 \times 1.0 \mathrm{~cm}^{3}\right)$. Detailed parameters are summarized in Table 1 and 3

\subsection{Molecular mass and polydispersity}

The differential curves of molecular mass distribution (MWD) for selected cases of the analyzed samples are shown in Figure 7.

a)

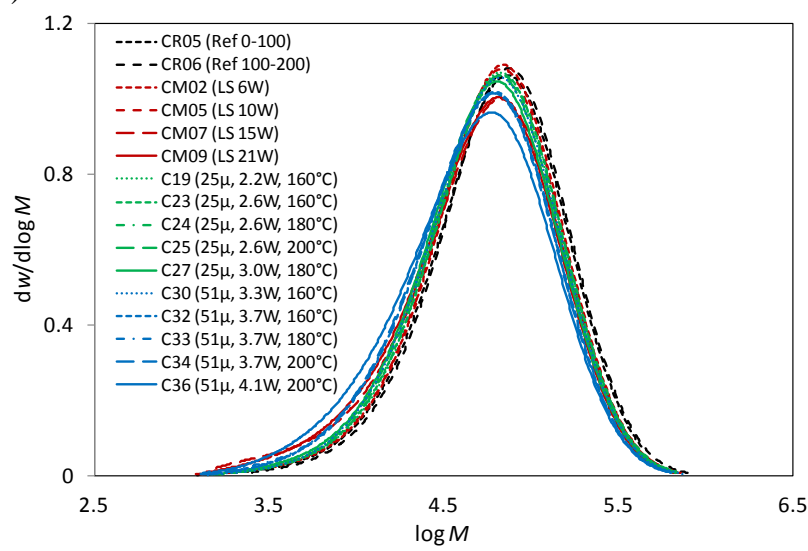

c)

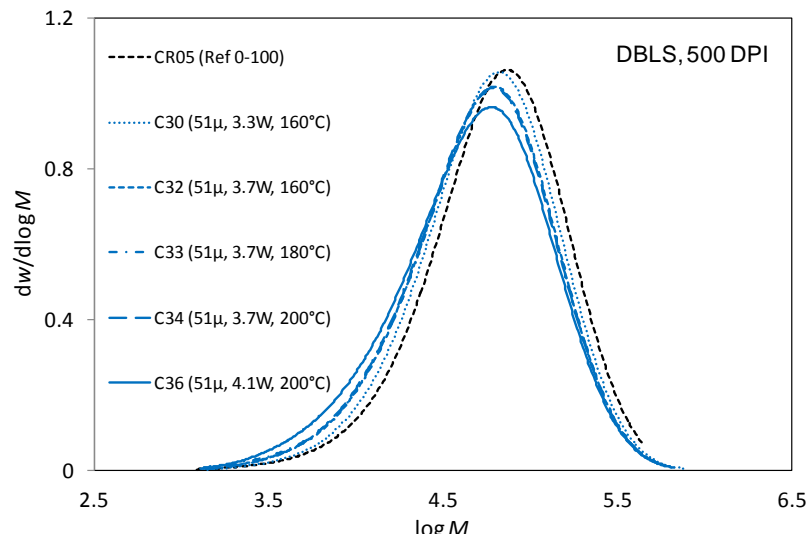

b)

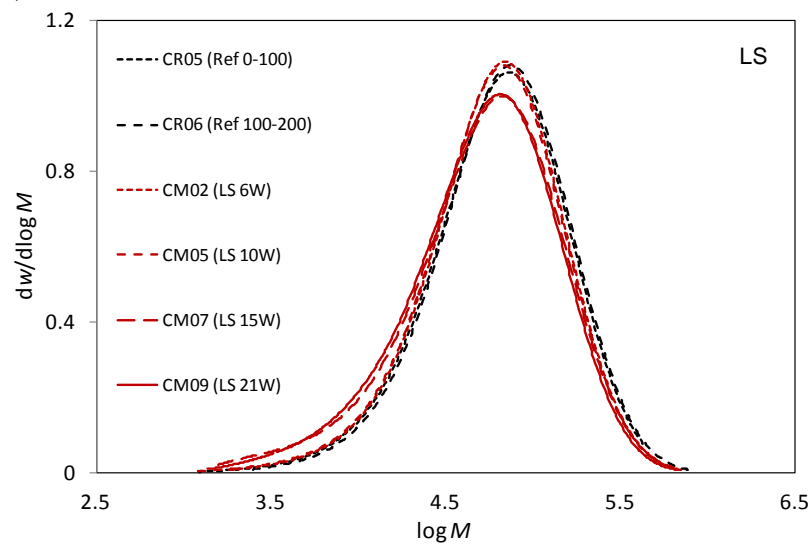

d)

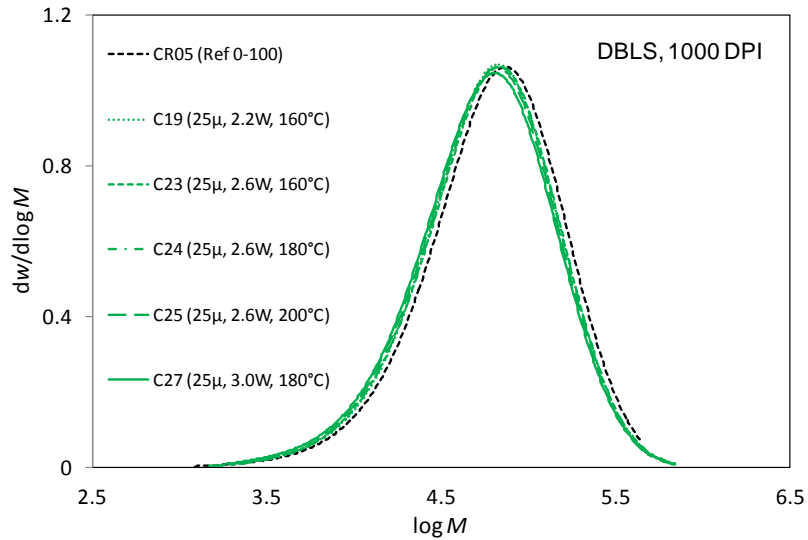

Fig. 7. Curves of the differential function of molecular mass distribution for sintered samples with different process parameters: a) compare of all curves, b) for standard LS processes, c) for DBLS method with a resolution of 500 DPI, e) for DBLS method with a resolution of 1000 DPI 
The number average and weight average molecular mass, respectively $M_{n}$ and $M_{w}$ expressed in polystyrene units, mean values of the PDI polydispersity index, all obtained from three SEC analyzes from a single solution or from two parallel solutions of the test samples are presented in Table 5. For a clear visualization of the changes mentioned above parameters, the $\mathrm{CHG}^{*}$ column also shows the percentage change of the parameter relative to the appropriate reference sample.

First of all, it is worth pay attention to post-process powder for both methods. Despite the fact that in the DBLS method, the powder was used to make several dozen samples (supplementing only the loss resulting from the sintering of the next sample), it is almost twice less degraded compared to the LS method, where it was used only for sintering one sample. This is due to the fact that in the DBLS method the powder is heated only in the boundary zone of the sintered sample (approx. $4.0 \mathrm{~mm}$ outside the contour of the sample) and the rest of it is not processed. This advantage will be of particular importance when a valuable medical grade material is to be sintered. In all analyzed cases, the MWD was unimodal, symmetrical and close to the normal distribution (Figure 7). We did not observe the bimodal distribution characteristic of the PLA ablation with $\mathrm{CO}_{2}$ laser [19]. Due to the large number of samples, which are difficult to compare on one graph - Figure 7a, they were compiled in series - Figure 7b-d, which enabled the analysis of which factors (process parameters) mainly influence the observed changes.

On a first overall analysis, it seems that both methods seem to show a fairly similar result in terms of changes in the relevant molecular weights and PDI. However, if the results obtained for the DBLS method are divided into two separate cases - in terms of process resolution - 500 and 1000 DPI, it can be seen that scanning with higher resolution gives a much lower loss of molecular weights (up to $46 \%$ for $M_{n}$ and up to $31 \%$ for $M_{w}$ ) compared to the LS method. This is because the denser scanning (laser pulses distributed every $25.4 \mu \mathrm{m}$ ) allows for a significant (about 30\% - comparing cases with the same degree of sintering) reduction of the sintering laser power in relation to the lower resolution of $500 \mathrm{DPI}(50.8 \mu \mathrm{m})$.

Table 5. Average values of $M_{n}, M_{w}$ and $M_{w} / M_{n}$ expressed in polystyrene units (PS)

\begin{tabular}{|c|c|c|c|c|c|c|c|c|c|c|c|c|c|}
\hline & \multirow{2}{*}{\multicolumn{4}{|c|}{$\begin{array}{c}\text { Process parameters / } \\
\text { description of the sample }\end{array}$}} & \multicolumn{3}{|c|}{$M_{n}$} & \multicolumn{3}{|c|}{$M_{w}$} & \multicolumn{3}{|c|}{$P D I$} \\
\hline name & & & & & {$[\mathrm{g} / \mathrm{mol}]$} & $\begin{array}{l}\text { RDS } \\
{[\%]} \\
\end{array}$ & $\begin{array}{c}\mathrm{CHG}^{*} \\
{[\%]}\end{array}$ & {$[\mathrm{g} / \mathrm{mol}]$} & $\begin{array}{l}\text { RDS } \\
{[\%]} \\
\end{array}$ & $\begin{array}{c}\mathrm{CHG}^{*} \\
{[\%]}\end{array}$ & $M_{w} / M_{n}$ & $\begin{array}{c}\text { RDS } \\
{[\%]} \\
\end{array}$ & $\begin{array}{c}\mathrm{CHG}^{*} \\
{[\%]}\end{array}$ \\
\hline CR05 & \multicolumn{4}{|c|}{ Ref $1-$ pure powder $(0-100 \mu \mathrm{m})$} & 41590 & 2.8 & - & 86683 & 2.0 & - & 2.08 & 1.5 & - \\
\hline CR06 & \multicolumn{4}{|c|}{ Ref $2-$ p. powder $(100-200 \mu \mathrm{m})$} & 45207 & 3.0 & - & 89157 & 1.3 & - & 1.97 & 1.9 & - \\
\hline CR04 & \multirow{2}{*}{\multicolumn{4}{|c|}{$\begin{array}{l}\text { powder after one processes of LS } \\
\text { after dozens processes of DBLS }\end{array}$}} & 40400 & 0.4 & -2.9 & 80983 & 0.7 & -6.6 & 2.01 & 0.8 & -3.4 \\
\hline \multirow[t]{2}{*}{ CR03 } & & & & & 40917 & 0.2 & -1.6 & 83470 & 0.3 & -3.7 & 2.04 & 0.5 & -1.9 \\
\hline & \multicolumn{4}{|c|}{$P_{S}[\mathrm{~W}]$} & \multicolumn{9}{|c|}{ Standard Laser Sintering method } \\
\hline CM02 & \multicolumn{4}{|c|}{$6 \mathrm{~W}$} & 38660 & 4.3 & -7.0 & 79840 & 1.2 & -7.9 & 2.06 & 3.2 & -1.0 \\
\hline CM05 & \multicolumn{4}{|c|}{$10 \mathrm{~W}$} & 37397 & 4.1 & -10.1 & 79677 & 1.0 & -8.1 & 2.13 & 3.2 & 2.4 \\
\hline CM07 & \multicolumn{4}{|c|}{15 W (compare to Ref_2) } & 30073 & 3.2 & -27.7 & 75623 & 1.6 & -15.2 & 2.52 & 4.7 & 25.4 \\
\hline CM09 & \multicolumn{4}{|c|}{21 W (compare to Ref_2) } & 29513 & 4.5 & -29.0 & 73297 & 1.4 & -17.8 & 2.49 & 3.6 & 23.9 \\
\hline & $h[\mu \mathrm{m}]$ & $P_{S}[\mathrm{~W}]$ & $T_{P}\left[{ }^{\circ} \mathrm{C}\right]$ & $T_{H}\left[{ }^{\circ} \mathrm{C}\right]$ & \multicolumn{9}{|c|}{ Dual Beam Laser Sintering method } \\
\hline C19 & \multirow{5}{*}{25.4} & 2.2 & 160 & 90 & 39237 & 1.6 & -5.7 & 80940 & 2.2 & -6.6 & 2.06 & 1.0 & -1.0 \\
\hline $\mathrm{C} 23$ & & \multirow{3}{*}{2.6} & 160 & 70 & 37863 & 4.1 & -9.0 & 80330 & 2.1 & -7.3 & 2.12 & 3.7 & 1.9 \\
\hline $\mathrm{C} 24$ & & & 180 & 100 & 38320 & 1.8 & -7.9 & 78843 & 1.2 & -9.0 & 2.06 & 1.0 & -1.0 \\
\hline $\mathrm{C} 25$ & & & 200 & 133 & 37267 & 0.7 & -10.4 & 76787 & 0.2 & -11.4 & 2.06 & 0.6 & -1.0 \\
\hline $\mathrm{C} 27$ & & 3.0 & 180 & 81 & 35053 & 3.2 & -15.7 & 76120 & 0.8 & -12.2 & 2.17 & 3.1 & 4.3 \\
\hline C30 & \multirow{5}{*}{50.8} & 3.3 & 160 & 64 & 36557 & 1.2 & -12.1 & 76693 & 1.0 & -11.5 & 2.10 & 1.7 & 1.0 \\
\hline C32 & & \multirow{3}{*}{3.7} & 160 & 72 & 32883 & 3.4 & -20.9 & 71863 & 1.5 & -17.1 & 2.19 & 1.8 & 5.3 \\
\hline C33 & & & 180 & 75 & 30797 & 4.0 & -26.0 & 70350 & 2.5 & -18.8 & 2.28 & 1.7 & 9.6 \\
\hline C34 & & & 200 & 113 & 30950 & 3.0 & -25.6 & 70330 & 0.4 & -18.9 & 2.27 & 2.9 & 9.1 \\
\hline C36 & & 4.1 & 200 & 104 & 27417 & 0.5 & -34.1 & 67120 & 0.6 & -22.6 & 2.45 & 0.5 & 17.8 \\
\hline
\end{tabular}

* - change in relation to the corresponding reference sample

The changes observed at the lower resolution are on average twice as large in relation to 1000 DPI. The second very important conclusion, which is somewhat related to it, is the fact that the observed changes (within the DBLS method) are a function of the sintering laser power $P_{S}$, not 
the process temperature $T_{P}$. For studies carried out for a different material (not presented in this paper), after modifying the laser system, it was also found that increasing the scanning speed allowed for a further significant reduction in the observed degradation. As there are several potential changes that can be implemented successively (e.g. changing the profile and diameter of the heating beam), the proposed method has further optimization potential.

\subsection{Infrared spectroscopy}

The spectra obtained (average of 64 measurements) after atmospheric correction are presented in Figure 8. Due to the slight differences between the bands for individual samples and to better visualize the changes that occurred in the chemical structure of polymers during the sintering of the material, the spectra of the treated samples (colored lines) were plotted on the reference spectra of the corresponding material (black lines). In the obtained spectra three fundamental region can be distinguished. Within the range of $1750-1735 \mathrm{~cm}^{-1}$ a very strong absorption band is visible which corresponds to the stretching vibrations of the carbonyl group $v(\mathrm{C}=\mathrm{O})$, characteristic for the aliphatic polyesters.

a)

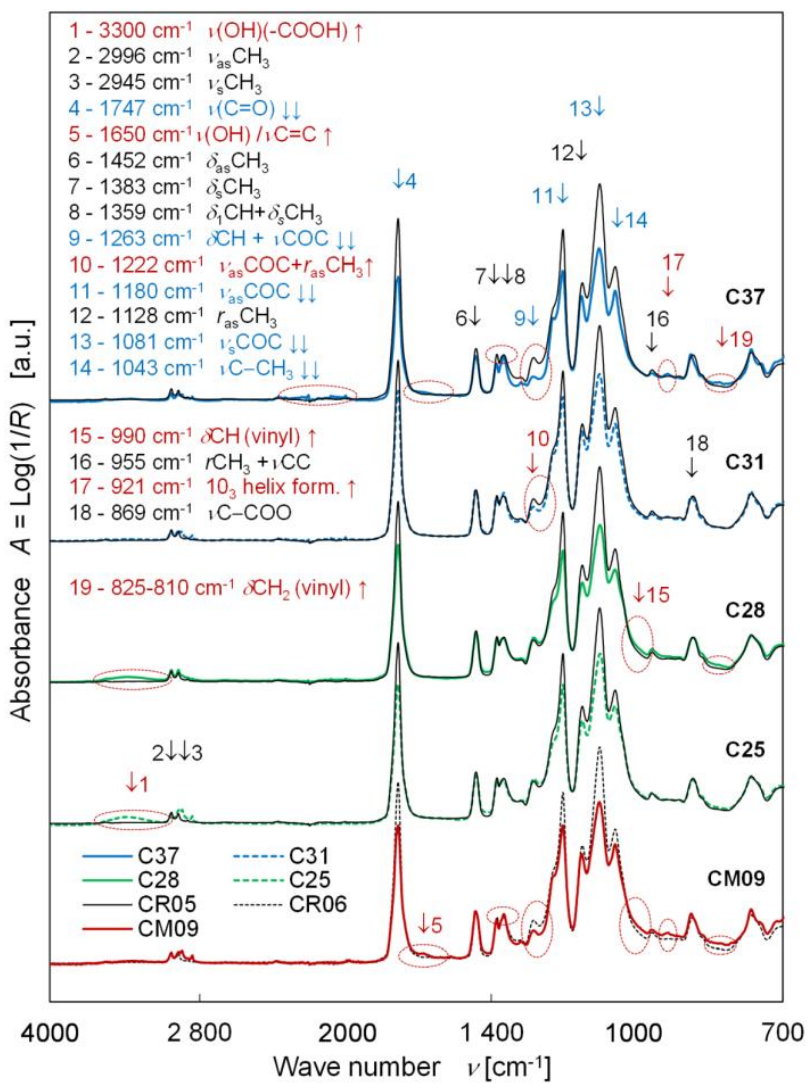

b)

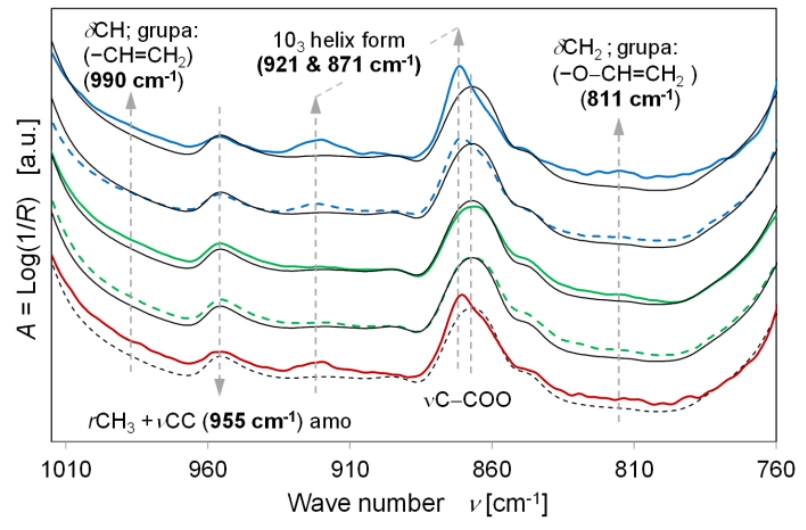

c)

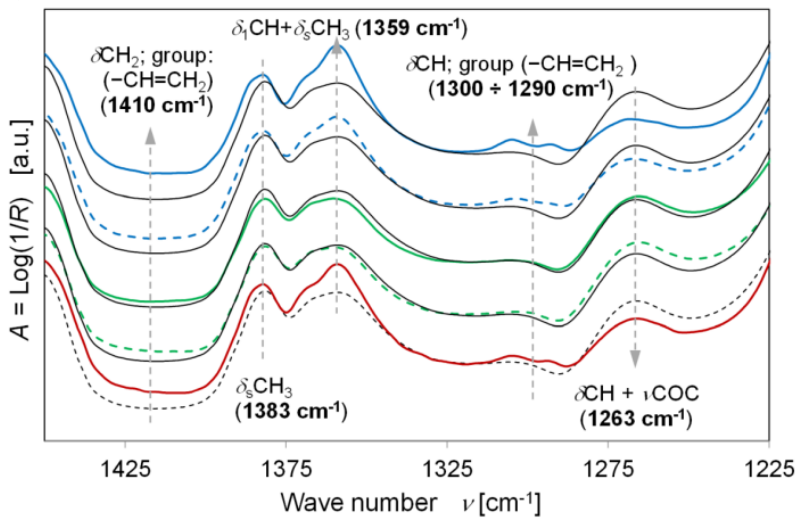

d)

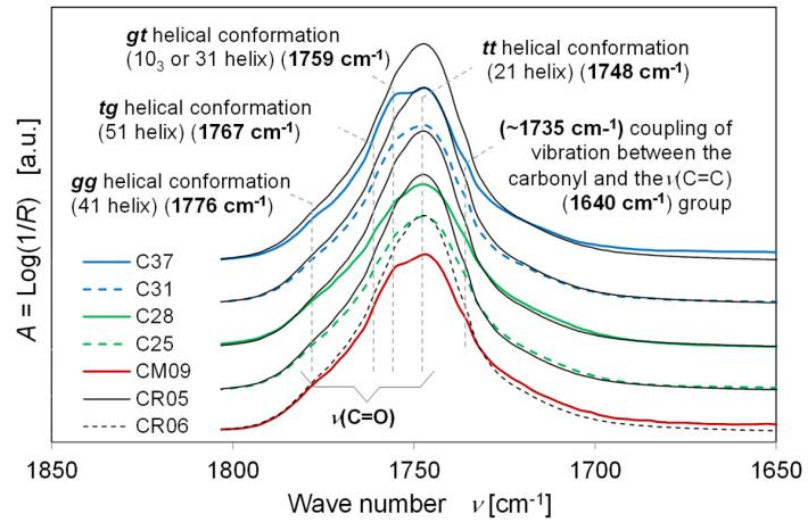

Fig. 8. ATR-FTIR spectra of selected samples of PLA sintered with a $\mathrm{CO}_{2}$ laser using the LS (red curves) and DBLS (blue curves - 500 DPI and green curves - 1000 DPI) methods presented against the background of the corresponding reference spectra (black curves): a) in the full spectral range of the measurement, b)-d) close-ups spectra for the bands $760-1100 \mathrm{~cm}^{-1}, \quad 1225-1450 \mathrm{~cm}^{-1}$ and $1650-1850 \mathrm{~cm}^{-1}$, respectively; measurements were made with a FTIR Nicolet 8700 spectrometer 
Next, in the $1500-1300 \mathrm{~cm}^{-1}$ range, there are several bands which are due to the deforming vibrations of the $\mathrm{CH}$ and $\mathrm{CH}_{3}$ groups. The $1300-1100 \mathrm{~cm}^{-1}$ range is a section where bands of symmetric and asymmetric valence vibrations occur of the $\downarrow \mathrm{COC}$ groups of the main chain. The analysis of FTIR spectra allows for two important findings. On their basis, it is possible to identify the potential degradation of the material manifested mainly by the appearance of bands not present in pure PLA, as well as to assess the change in the degree of crystallinity of the material. For all samples, there was a significant reduction in the intensity of the $1747 \mathrm{~cm}^{-1}$ band, which would directly indicate a reduction in the number of aliphatic ester segments.

An analogous decrease in the intensities of the bands responsible for the asymmetric $v_{a s} \mathrm{COC}$ $\left(1180 \mathrm{~cm}^{-1}\right)$ and symmetrical $v_{s} \mathrm{COC}\left(1081 \mathrm{~cm}^{-1}\right)$ vibrations group COC, respectively, was noted, indicating a defragmentation of the chains within this group. Moreover, the correlation of the spectrograms for the reference materials and the sintered samples nos. C37, C31 (DBLS; $500 \mathrm{DPI} ; P_{S}=3.3$ and $\left.4.1 \mathrm{~W}\right)$ and CM09 (LS; $P_{S}=21 \mathrm{~W}$ ) showed the appearance of several very small but characteristic absorption bands 1410, 1295, 990 and $811 \mathrm{~cm}^{-1}$ of vinyl groups $\left(\mathrm{RCH}=\mathrm{CH}_{2}\right)$ responsible for the deforming vibration in the plane of the $\delta \mathrm{CH}_{2}$ and $\delta \mathrm{CH}$ bonds for hydrocarbon compounds in the bands of $\left(1420-1410 \mathrm{~cm}^{-1}\right.$ and $\left.1300-1290 \mathrm{~cm}^{-1}\right)$ respectively, and out of the plane of the $\delta \mathrm{CH}$ and $\delta \mathrm{CH}_{2}$ bonds, for ketones $\left(\mathrm{RCOCH}=\mathrm{CH}_{2}\right)$ and/or vinyl ethers $\left(\mathrm{ROCH}=\mathrm{CH}_{2}\right)\left(995-980 \mathrm{~cm}^{-1}\right)$ and ethers $\left(825-810 \mathrm{~cm}^{-1}\right)$, respectively [26]. A very small increase in the valence vibration band $v(C=C)$ around $1650 \mathrm{~cm}^{-1}$ (Figure $8 \mathrm{a}$ and c) was also recorded, which is characteristic for the double carbon bond $(\mathrm{C}=\mathrm{C})$ and confirms the aboveobserved changes. There is also an extension of the band $v(\mathrm{C}=\mathrm{O}) 1747 \mathrm{~cm}^{-1}$ in the direction of lower frequencies $\left(1735 \mathrm{~cm}^{-1}\right)$, which is due to the coupling of vibration between the carbonyl group and the $v(\mathrm{C}=\mathrm{C})$ group. The mentioned changes are visible on the enlarged fragments of the analyzed spectra - Figure $8 \mathrm{~b}$ and $\mathrm{c}$. It is worth noting that most of these bands are not noticeable for samples sintered by the DBLS method with a resolution of 1000 DPI, which correlates well with the GPC results.

Other changes visible on spectrograms within bands 1359, 1263, 955, 921 and $871 \mathrm{~cm}^{-1}$ result from changes in the degree of crystallinity of the samples. For samples nos. C37, C31 and CM09, a significant increase in the degree of crystallinity was noted. The $960-830 \mathrm{~cm}^{-1}$ region (backbone stretching and $\mathrm{CH}_{3}$ rocking) is sensitive to the degree of crystallinity. As shown in the works $[27,28]$ both the bands at 921 and $871 \mathrm{~cm}^{-1}$ are related to the crystals in the $\alpha$ form with a distorted $10_{3}$ helix conformation of PLA, and that the band at $921 \mathrm{~cm}^{-1}$ corresponds to a shorter critical sequence length than that of the band at $871 \mathrm{~cm}^{-1}$. It has also been revealed that the bands at $955 \mathrm{~cm}^{-1}$ reflect the amorphous state of PLA. The increase in the degree of crystallinity is also visible within the carbonyl group. During crystallization, PLA decomposes into four peaks located at 1776, 1767, 1759 and $1748 \mathrm{~cm}^{-1}$ [29]. The strongest band gain is visible at $1759 \mathrm{~cm}^{-1}$ for the samples C37 and CM09. In this band, both the $\alpha$ and $\alpha^{\prime}$ phases can crystallize and it cannot be distinguished here. There was no change in the degree of crystallinity for the samples sintered with a resolution of 1000 DPI.

\subsection{Differential scanning calorimetry}

The DSC measurement were performed in order to compare PLA samples sintered on DBLS and standard LS system and to investigate the effect of laser sintering process parameters on thermal properties of PLA. The DSC analysis enable comparison of thermomechanical history of the printed samples and provides information for optimization of the processing parameters. The first heating DSC curves of sintered details are presented on Figure 9 and the estimated thermal parameters are collected in Table 6 . The most prominent differences between the first heating DSC curves of the sintered samples and also comparing to reference microspheres concern melting and cold crystallization. In case of PLA sintered on DBLS tree maxima are visible on the endotherm of melting whereas for PLA sintered on commercial LS printer even four maxima are distinguishable. 
a)

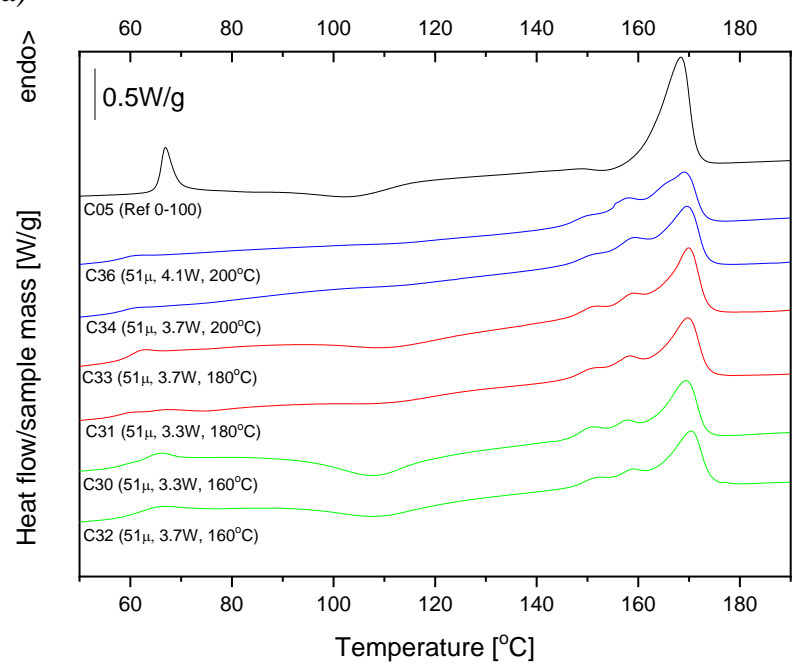

.

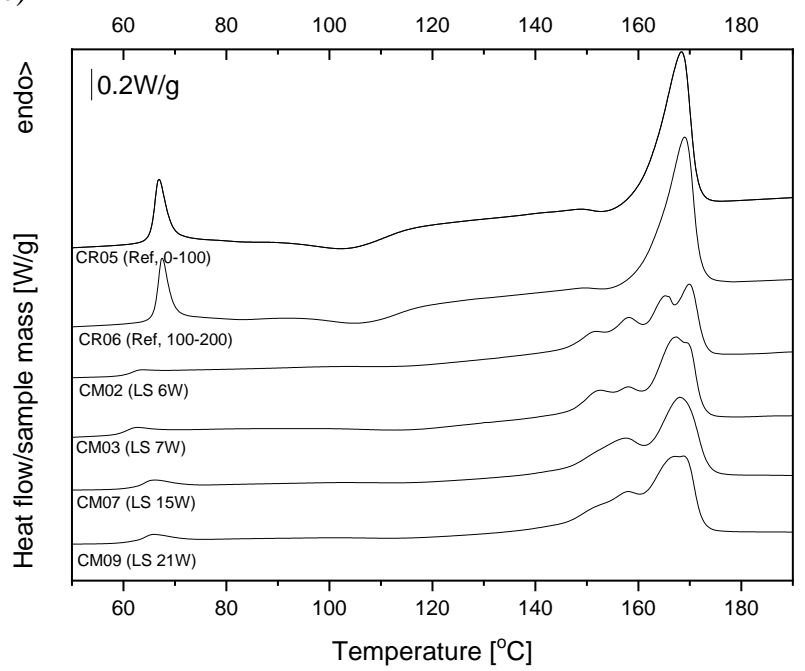

b)

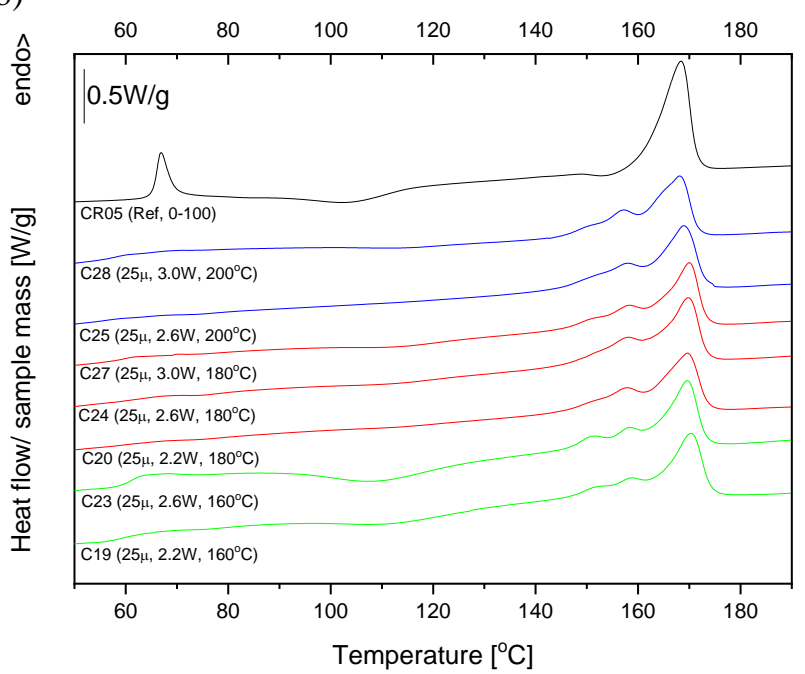

Fig. 9. The first heating DSC curves of PLA samples sintered with a) resolution of $500 \mathrm{DPI}$, and b) $1000 \mathrm{DPI}$ on DBLS and on c) standard LS systems

The influence of processing parameters on cold crystallization behavior of printed samples can be evaluated based on the analysis of the samples sintered on DBLS with 500 DPI resolution (Figure 9a). For samples sintered with the process temperature of $160^{\circ} \mathrm{C}$ and with the lowest laser heating temperature $T_{H}=64^{\circ} \mathrm{C}(\mathrm{C} 30)$ the enthalpy of cold crystallization $\left(\Delta H_{c c}\right)$ reached the highest value $(34 \mathrm{~J} / \mathrm{g})$. This could be explained that the PLA powder was partially melted by laser beams and during cooling and during father processing and staying in bed cold crystallization does not occur, because the temperature of laser heating beam was lower than $T_{g}$. For sample C32 sintered at this same processing temperature but with higher $T_{H}=72^{\circ} \mathrm{C}$ the $\Delta H_{c c}$ is lower about $14 \mathrm{~J} / \mathrm{g}$, but still higher comparing to reference polymer powder (CR05). This same trend of lower $\Delta H_{c c}$ for higher $T_{H}$ is present in case of samples sintered with processing temperatures of $180^{\circ} \mathrm{C}(\mathrm{C} 31, \mathrm{C} 33)$ and $200^{\circ} \mathrm{C}(\mathrm{C} 34, \mathrm{C} 36)$.

At the same time, with increasing processing temperature onset $\left(T_{c c}{ }^{\text {onset }}\right)$ and maximum $\left(T_{c c}{ }^{\text {peak }}\right)$ of cold crystallization peak are shifted to higher temperatures of about $4.0^{\circ} \mathrm{C}$ and $11.1^{\circ} \mathrm{C}$. This indicate on changes in crystal form that developed on heating. It is known that depending on the crystallization temperature, the less ordered $\alpha^{\prime}$ and ordered $\alpha$ phases of poly(Llactide) are formed at low $\left(T_{c}<100^{\circ} \mathrm{C}\right)$ and high $\left(T_{c}>120^{\circ} \mathrm{C}\right)$ temperatures, respectively [30]. In our case the $T_{c c}$ are in intermediate range, but trend of increasing $T_{c c}$ in comparison to the reference is clearly visible. Moreover, localization of cold crystallization (onset and peak maximum) is dependent on processing temperature $T_{P}$, whereas the enthalpy of cold crystallization depends on $T_{H}$.

Melting peak of PLA sintered on DBLS has tree maxima denoted as $T_{m}{ }^{1}, T_{m}{ }^{2}, T_{m}{ }^{3}$ in order of decreasing temperature. The assignment of this maxima needs additional investigation of crystalline structure of as printed PLA and as well reference and sintered samples after the first heating scan. 
Table 6. Thermal parameters estimated form the first heating DSC curves of PLA samples sintered on DBLS and standard LS systems

\begin{tabular}{|c|c|c|c|c|c|c|c|c|c|c|c|c|}
\hline $\begin{array}{l}\text { Sample } \\
\text { name }\end{array}$ & \multicolumn{4}{|c|}{$\begin{array}{l}\text { Process parameters / description } \\
\text { of the sample }\end{array}$} & $\begin{array}{c}T_{g} \\
{\left[{ }^{\circ} \mathrm{C}\right]}\end{array}$ & $\begin{array}{c}T_{c c} \\
{\left[{ }^{\circ} \mathrm{C}\right]}\end{array}$ & $\begin{array}{l}\Delta H_{c c} \\
{[\mathrm{~J} / \mathrm{g}]}\end{array}$ & $\begin{array}{c}T_{m}^{4} \\
{\left[{ }^{\circ} \mathrm{C}\right]}\end{array}$ & $\begin{array}{l}T_{m}{ }^{3} \\
{\left[{ }^{\circ} \mathrm{C}\right]}\end{array}$ & $\begin{array}{l}T_{m}{ }^{2} \\
{\left[{ }^{\circ} \mathrm{C}\right]}\end{array}$ & $\begin{array}{c}T_{m}{ }^{1} \\
{\left[{ }^{\circ} \mathrm{C}\right]}\end{array}$ & $\begin{array}{l}\Delta H_{m} \\
{[\mathrm{~J} / \mathrm{g}]}\end{array}$ \\
\hline CR05 & \multicolumn{4}{|c|}{ Ref $1-$ pure powder $(0-100 \mu \mathrm{m})$} & 65.9 & 103.6 & -11.7 & - & - & - & 168.8 & 42.8 \\
\hline CR06 & \multicolumn{4}{|c|}{ Ref $2-$ p.powder $(100-200 \mu \mathrm{m})$} & 66.6 & 106.5 & -9.7 & - & - & - & 168.8 & 42.6 \\
\hline & \multicolumn{4}{|c|}{$P_{S}[\mathrm{~W}]$} & & & & & & & & \\
\hline CM02 & \multicolumn{4}{|c|}{$6 \mathrm{~W}$} & 61.7 & 115.2 & -4.9 & 152.0 & 158.0 & 165 & 169.6 & 37.8 \\
\hline CM03 & \multicolumn{4}{|c|}{$7 \mathrm{~W}$} & 60.5 & 114.9 & -6.0 & 152.5 & 158.0 & 167.1 & 171.0 & 42.3 \\
\hline CM07 & \multicolumn{4}{|c|}{15 W (compare to Ref_2) } & 64.0 & 115.6 & -1.5 & - & 157.5 & 167.8 & - & 46.7 \\
\hline CM09 & \multicolumn{4}{|c|}{21 W (compare to Ref_2) } & 64.1 & 113.5 & -1.6 & - & 158.0 & 166.5 & 168.7 & 49.5 \\
\hline & $h[\mu \mathrm{m}]$ & $P_{S}[\mathrm{~W}]$ & $T_{P}\left[{ }^{\circ} \mathrm{C}\right]$ & $T_{H}\left[{ }^{\circ} \mathrm{C}\right]$ & & & & & & & & \\
\hline $\mathrm{C} 19$ & \multirow{7}{*}{25.4} & \multirow{2}{*}{2.2} & 160 & 90 & 58.7 & 111.8 & -15.9 & - & 152.0 & 159.0 & 169.8 & 36.9 \\
\hline $\mathrm{C} 20$ & & & 180 & 112 & 58.7 & 114.7 & -6.7 & - & - & 158.0 & 169.2 & 37.0 \\
\hline $\mathrm{C} 23$ & & \multirow{3}{*}{2.6} & 160 & 70 & 60.9 & 108.9 & -28.4 & - & 151.5 & 158.5 & 169.1 & 36.8 \\
\hline $\mathrm{C} 24$ & & & 180 & 100 & 59.6 & 113.7 & -9.1 & - & - & 158.0 & 169.2 & 39.5 \\
\hline $\mathrm{C} 25$ & & & 200 & 133 & 55.6 & 113.5 & -6.3 & - & - & 158.0 & 168.6 & 39.5 \\
\hline $\mathrm{C} 27$ & & \multirow{2}{*}{3.0} & 180 & 81 & 59.4 & 113.6 & -12.3 & - & - & 158.2 & 169.6 & 36.6 \\
\hline $\mathrm{C} 28$ & & & 200 & 100 & 57.9 & 112.2 & -9.4 & - & - & 157.5 & 167.6 & 37.4 \\
\hline $\mathrm{C} 30$ & \multirow{6}{*}{50.8} & \multirow{2}{*}{3.3} & 160 & 64 & 63.0 & 108.1 & -34.0 & - & 151.0 & 158.0 & 169.1 & 35.6 \\
\hline C31 & & & 180 & 109 & 57.7 & 111.0 & -9.7 & - & 151.5 & 158.5 & 169.2 & 40.0 \\
\hline C32 & & \multirow{3}{*}{3.7} & 160 & 72 & 62.6 & 108.4 & -20.0 & - & 152.0 & 159.0 & 170.0 & 35.4 \\
\hline $\mathrm{C} 33$ & & & 180 & 75 & 60.0 & 111.2 & -20.9 & - & 152.0 & 159.0 & 169.4 & 41.4 \\
\hline C34 & & & 200 & 113 & 58.6 & 114.7 & -3.9 & - & 152.0 & 159.0 & 169.2 & 43.4 \\
\hline C36 & & 4.1 & 200 & 104 & 58.2 & 114.2 & -8.4 & - & 150.0 & 158.2 & 168.6 & 39.7 \\
\hline
\end{tabular}

We propose some interpretation of the melting behavior based on the analysis of the measured DSC curves. The maximum at the lowest temperature $\left(T_{m}{ }^{3}\right)$ is getting more visible for samples that have higher values of $\Delta H_{c c}(\mathrm{C} 30-\mathrm{C} 33)$. Thus, it can be attributed to melting of crystal fraction that was formed during cold crystallization on recording of the first heating DSC curve. The highest maximum of melting peak corresponds to melting of crystallites originally present in reference material that was not melted during processing. The $T_{m}{ }^{1}$ of the reference CR05 was found at $168.8^{\circ} \mathrm{C}$ and for sintered samples the values are similar. The multiple melting arise from spatial distribution of different crystals as a result of laser induced thermal gradient "written" by laser beams during scanning. It should also be aware that the material changes on heating during recording of the DSC curve. Moreover, beyond any doubt the presence of lower molecular mass PLA, as indicated by GPC, have influence on crystallization and melting behaviors of PLA.

The melting enthalpy $\left(\Delta H_{m}\right)$ of PLA sintered at the lowest processing temperature and as well at the lowest $T_{H}(\mathrm{C} 30)$ is c.a. $16 \%$ lower than the reference. This could be explained in two ways: that PLA was partially melted during LS processing and crystallization of sintered PLA is restricted, the PLA after LS processing cannot reach the crystallinity level as the reference PLA. Or that lower $\Delta H_{m}$ steam from higher content of $\alpha$ ' phase. The melting enthalpy of $100 \%$ crystalline $\alpha$ ' PLLA crystals is lower than $\alpha$ PLLA crystals [31]. Referring to FTIR results indicating on increased crystallinity of some sintered PLA samples, we are inclined that $\alpha$ ' crystals were developed that have lower melting enthalpy.

Degradation of PLA is also visible in the DSC results. The glass transition temperature $\left(T_{g}\right)$ estimated form the first heating scan is shifted to lower values with increasing processing temperature and for the samples sintered at the same $T_{P}$ is lower for samples sintered with higher $T_{H}$. Lowering of $T_{g}$ can be ascribed to lowering of mean molecular mass due to thermal degradation of PLA. The trends of lowering of $T_{g}$ with increasing $T_{P}$ is in agreement with GPC results. Differences observed in the temperature range of cold crystallization and melting are thus analogous for samples sintered with 1000 DPI (Figure 9b). The trends of changes in enthalpies and characteristic temperatures of phase transitions depending on the processing temperatures $T_{P}$ and $T_{H}$ are the same as for $500 \mathrm{DPI}$, but weaker. 
The DSC curves of PLA sintered on commercial LS printer are presented on Figure 9c. The most characteristic thermal feature comparing to PLA samples sintered on DBLS is melting endotherm with four maxima. Existence of this maxima indicates on different crystal structures that were developed in thermal gradient induced by laser beam. This could also be connected with melting of crystals of lower molecular weight PLA. The presence of four in place of tree maxima such in PLA sintered on DBLS could be explained by differences in scanning resolution of laser beams used in both printers. Partial blurring of the maxima in the case of the PLA sintered with the highest power $15 \mathrm{~W}$ and $21 \mathrm{~W}$ (CM07 and CM09) is due to the fact that the samples have been melted more strongly and indicate on flow of PLA. This samples are stronger sintered comparing to other sintered with lower power. Also $\Delta H_{m}$ of this samples is the highest and even higher than reference. This could steam form presence of higher content of lower molecular mass PLA, that increase crystallinity degree due to faster crystallization.

\section{Conclusions}

The paper presents a new method of dual beam laser sintering of polymers (DBLS). The design and principle of operation of the prototype version of the device, based on the adaptation of a classic plotter system for subtractive laser processing, has been presented. With the use of the constructed station, an experiment was carried out, consisting in sintering samples from technical polylactide powder as a function of selected process parameters. The experiment confirmed the functionality of the method and proved that the sintering process can be controlled in a fairly wide range for the proposed method. Moreover, a preliminary comparison of changes in the physicochemical properties of the obtained samples was carried out in relation to the samples sintered with standard laser sintering (LS). This comparison made it possible to conclude that the presented method has the potential to limit the thermal degradation of sensitive polymer materials in relation to the standard LS. This is due to the fact that the material is not heated in its entire volume and for the entire duration of the process. Thus, lower degradation of the postprocess powder was demonstrated. It has been shown that material degradation in the doublebeam laser sintering method is primarily a function of the sintering laser power $P_{S}$, and not the process temperature $T_{P}$. Moreover, it was found that another way to reduce the degradation is to increase the resolution of the process, as it allows the reduction of the aforementioned sintering laser power. The aim of this study was not to prove that the proposed method degrades the material to a lesser extent, but only to present the method and demonstrate its potential. The authors realize that a reliable comparison of the degree of degradation induced by the proposed method requires more objective comparative techniques, which is the subject of further studies.

\section{Acknowledgments}

The research was supported by project Opus "Laser modification of bioresorbable polymeric materials in thermic processes of additive manufacturing" financed by National Centre of Science (UMO-2017/27/B/ST8/01780).

\section{References}

[1] I. Gibson, D. Rosen, B. Stucker, M. Khorasani, Additive manufacturing technologies, Springer, New York, 2014.

[2] B. Duan, M. Wang, Selective laser sintering and its application in biomedical engineering. MRS Bull. 36 (2011) 998-1005. https://doi.org/10.1557/mrs.2011.270.

[3] P. Szymczyk-Ziółkowska, M.B. Łabowska, J. Detyna, I. Michalak, P. Gruber, A review of fabrication polymer scaffolds for biomedical applications using additive manufacturing techniques. Biocybern. Biomed. Eng. 40 (2010) 624-638. https://doi.org/10.1016/j.bbe.2020.01.015.

[4] W.Y. Yeong, C.K. Chua, K.F. Leong, M. Chandrasekaran, Rapid prototyping in tissue engineering: challenges and potential. Trends Biotechnol 22 (2004) 643-652. https://doi.org/10.1016/j.tibtech.2004.10.004

[5] C.R. Deckard, J.J. Beaman, J.F. Darrah, Method and Apparatus for Producing Parts by Selective Sintering, Patent US5155324 A (1992).

[6] M. Schmid, Laser Sintering with Plastics, Carl Hanser Verlag GmbH \& Co., Munich, 2018. 
[7] Y. Zhou, S. Xi, Y. Huang, M. Kong, Q. Yang, G. Li, Preparation of near-spherical PA12 particles for selective laser sintering via Plateau-Rayleigh instability of molten fibers. Mater. Des. 190 (2020) 108578. https://doi.org/10.1016/j.matdes.2020.108578.

[8] S. Griessbach, Method For Preparing Waste Powder From Generative Production Processes, Patent WO/2018/028728 (2018).

[9] F.M. Verboom, Method For At Least Substantially Regenerating Polymer Powder, Patent WO/2016/010424 (2016).

[10] Materialise, Manufacturing Breakthrough Creates Path towards Eliminating Waste in 3D Printing. https://www.materialise.com/en/press-releases/manufacturing-breakthrough-creates-path-towardseliminating-waste-in-3d-printing, 2020 (accessed 18 November 2020).

[11] H. Tamai, K. Igaki, E. Kyo, K. Kosuga, A. Kawashima, S. Matsui, H. Komori, T. Tsuji, S. Motohara, H. Uehata, Initial and 6-month results of biodegradable poly-1-lactic acid coronary stents in humans. Circulation 102 (2000) 399-404. https://doi.org/10.1161/01.CIR.102.4.399.

[12] J.C. Middleton, A.J. Tipton, Synthetic biodegradable polymers as orthopedic devices. Biomaterials 21 (2000) 2335-2346. https://doi.org/10.1016/S0142-9612(00)00101-0.

[13] S. Commandeur, H.M. van Beusekom, W.J. van der Giessen, Polymers, drug release, and drug-eluting stents. J. Interv. Cardiol. 19 (2006) 500-506. https://doi.org/10.1111/j.1540-8183.2006.00198.x.

[14] A. Mazzoli, Selective laser sintering in biomedical engineering. Med. Biol. Eng. Comput. 51 (2013) $245-256$. https://doi.org/10.1007/s11517-012-1001-X.

[15] M. Van den Eynde, P. Van Puyvelde, 3D Printing of Poly (lactic acid), in. M.L. DiLorenzo, R. Androsch (Eds.), Industrial Applications of Poly (lactic acid), Springer Verlag, 2018, pp. 139-158.

[16] D.S. Kim, S.W. Bae, K.H. Choi, Development of industrial SFF system using dual laser and optimal process. Robot. Comput. Integr. Manuf. 23 (2007) 659-666. https://doi.org/10.1016/j.rcim.2007.02.007.

[17] C.N. Sun, M.C. Gupta, Laser sintering of ZrB2. J. Am. Ceram. Soc. 91 (2008) 1729-1731. https://doi.org/10.1111/j.1551-2916.2008.02369.x.

[18] F. Abe, K. Osakada, M. Shiomi, K. Uematsu, M. Matsumoto, The manufacturing of hard tools from metallic powders by selective laser melting. J. Mater. Process. Technol. 111 (2001) 210-213. https://doi.org/10.1016/S0924-0136(01)00522-2.

[19] A.J. Antończak, B.D. Stępak, K. Szustakiewicz, M.R. Wójcik, K.M. Abramski, Degradation of poly (1lactide) under $\mathrm{CO}_{2}$ laser treatment above the ablation threshold. Polym. Degrad. Stab., 109 (2014) 97-105. https://doi.org/10.1016/j.polymdegradstab.2014.07.004.

[20] F.D. Kopinke, M. Remmler, K. Mackenzie, M. Möder, O. Wachsen, Thermal decomposition of biodegradable polyesters - II. Poly (lactic acid). polymer Polym. Degrad. Stab. 53 (1996) 329-342. https://doi.org/10.1016/0141-3910(96)00102-4.

[21] I.C. McNeill, H.A. Leiper, Degradation studies of some polyesters and polycarbonates - 2. Polylactide: degradation under isothermal conditions, thermal degradation mechanism and photolysis of the polymer. Polym. Degrad. Stab. 11 (1985) 309-326. https://doi.org/10.1016/0141-3910(85)90035-7.

[22] Y. Fan, H. Nishida, Y. Shirai, T. Endo, Control of racemization for feedstock recycling of PLLA. Green Chem. 5 (2003) 575-579. https://doi.org/10.1039/B304792J.

[23] H. Tsuji, I. Fukui, H. Daimon, K. Fujie, Poly (L-lactide) XI. Lactide formation by thermal depolymerisation of poly (L-lactide) in a closed system. Polym. Degrad. Stab. 81 (2003) 501-509. https://doi.org/10.1016/S0141-3910(03)00150-2.

[24] C. Mielicki, B. Gronhoff, J. Wortberg, Effects of laser sintering processing time and temperature on changes in polyamide 12 powder particle size, shape and distribution, in: AIP Conf. Proc. American Institute of Physics, 2014. pp. 728-731. https://doi.org/10.1063/1.4873880.

[25] M. Olejarczyk, P. Gruber, G. Ziółkowski, Capabilities and Limitations of Using Desktop 3-D Printers in the Laser Sintering Process. Appl. Sci. 10 (2020) 6184. https://doi.org/10.3390/app10186184.

[26] G. Socrates, Infrared and Raman characteristic group frequencies: tables and charts. John Wiley \& Sons, 2001, pp. 74.

[27] J. Zhang, H. Tsuji, I. Noda, Y. Ozaki, Weak intermolecular interactions during the melt crystallization of poly (L-lactide) investigated by two-dimensional infrared correlation spectroscopy. J. Phys. Chem. B. 108 (2004) 11514-11520. https://doi.org/10.1021/jp048308q.

[28] V. Krikorian, D.J. Pochan, Crystallization behavior of poly (L-lactic acid) nanocomposites: nucleation and growth probed by infrared spectroscopy. Macromolecules 38 (2005) 6520-6527. https://doi.org/10.1021/ma050739z.

[29] E. Meaurio, E. Zuza, N. López-Rodríguez, J.R. Sarasua, Conformational behavior of poly (L-lactide) studied by infrared spectroscopy. J. Phys. Chem. B. 110 (2006) 5790-5800. https://doi.org/10.1021/jp055203u.

[30] J. Zhang, K. Tashiro, H. Tsuji, A.J. Domb, Disorder-to-order phase transition and multiple melting behavior of poly (L-lactide) investigated by simultaneous measurements of WAXD and DSC. Macromolecules 41 (2008) 1352-1357. https://doi.org/10.1021/ma0706071.

[31] R. Androsch, C. Schick, M.L. Di Lorenzo, Melting of Conformationally Disordered Crystals ( $\alpha^{\prime}$-Phase) of Poly (l-lactic acid). Macromol. Chem. Phys. 215 (2014) 1134-1139. https://doi.org/10.1002/macp.201400126. 